\title{
MESENCHYMAL STROMAL CELLS FROM HUMAN UMBILICAL CORDS DISPLAY POOR CHONDROGENIC POTENTIAL IN SCAFFOLD-FREE THREE DIMENSIONAL CULTURES
}

\author{
A. Islam ${ }^{1}$, A.K. Hansen ${ }^{1,2}$, C. Mennan ${ }^{3}$ and I. Martinez-Zubiaurre ${ }^{1 *}$ \\ ${ }^{1}$ Institute of Clinical Medicine, University of Tromsø, Tromsø, 9037, Norway \\ ${ }^{2}$ Department of Orthopaedic and Plastic Surgery, University Hospital of North Norway, Tromsø, 9038, Norway \\ ${ }^{3}$ The Robert Jones and Agnes Hunt Orthopaedic Hospital NHS Foundation Trust and ISTM, Keele University, \\ Oswestry, SY10 7AG, UK
}

\begin{abstract}
Many researchers world over are currently investigating the suitability of stromal cells harvested from foetal tissues for allogeneic cell transplantation therapies or for tissue engineering purposes. In this study, we have investigated the chondrogenic potential of mesenchymal stromal cells (MSCs) isolated from whole sections of human umbilical cord or mixed cord (UCSCs-MC), and compared them with cells isolated from synovial membrane (SMSCs), Hoffa's fat pad (HFPSCs) and cartilage. All MSCs were positive for surface markers including CD73, CD90, CD105, CD44, CD146 and CD166, but negative for CD11b, CD19, CD34, CD45 and HLA-DR in addition to CD106 and CD271. Chondrogenic potential of all cell sources was studied using 3D pellet cultures incubated in the presence of different combinations of anabolic substances such as dexamethasone, IGF-1, TGF- $\beta 1$, TGF- $\beta 3$, BMP-2 and BMP-7. BMP-2 and dexamethasone in combination with TGF- $\beta 1$ or TGF- $\beta 3$ excelled at inducing chondrogenesis on SMSCs, HFPSCs and chondrocytes, as measured by glycosaminoglycans and collagen type II staining of pellets, quantitative glycosaminoglycan expression, quantitative PCR of cartilage signature genes and electron microscopy. In contrast, none of the tested growth factor combinations was sufficient to induce chondrogenesis on UCSCs-MC. Moreover, incubation of UCSCs-MC spheroids in the presence of cartilage pieces or synovial cells in co-cultures did not aid chondrogenic induction. In summary, we show that in comparison with MSCs harvested from adult joint tissues, UCSCs-MC display poor chondrogenic abilities. This observation should alert researchers at the time of considering UCSCs-MC as cartilage forming cells in tissue engineering or repair strategies.
\end{abstract}

Keywords: Chondrogenesis; 3D pellet culture; Mesenchymal stromal cells, Umbilical cord derived stromal cells; Hoffa's fat pad derived stromal cells; Synovial membrane derived stromal cells.

\footnotetext{
*Address for correspondence:

Inigo Martinez-Zubiaurre

Institute of Clinical Medicine

University of Tromsø

Tromsø, 9037, Norway
}

Telephone number: +4777644686

Email: inigo.martinez@uit.no

\section{Introduction}

Articular cartilage is a specialised avascular and hypocellular load-bearing tissue that covers the terminal edges of adjacent bones and provides frictionless movement of the joints (Hunziker, 2002). Lesions in articular cartilage evolving from traumatic or pathological processes represent a very common clinical condition in both developed and developing countries, and show increasing prevalence due to the steady prolongation of life expectancy (Beris et al., 2005). During the last decades biological repair of cartilage has been attempted by both the direct implantation of autologous cells, (Brittberg, 2008) and by the ex-vivo generation of tissue engineering-based implants (Filardo et al., 2013). Despite promising achievements in the laboratory and in animal models, clinical translation of these techniques remains very limited.

One of the main obstacles encountered is the limited availability of donor tissue, along with some ethical constraints associated with painful harvesting and possible donor site morbidity (Horas et al., 2003). Furthermore, articular chondrocytes used in autologous chondrocyte implantation (ACI) or bone marrow-derived MSCs (bMSCs) have been shown to gradually lose proliferative and differentiation potential in vitro in relation to increasing patient age (Mueller and Glowacki, 2001; Roobrouck et al., 2008; Smeriglio et al., 2015). In the clinic, the procedures mentioned above are often associated with the formation of biomechanically inferior fibrocartilage in the repair zone (Horas et al., 2003; Wright et al., 2013). Hence, approximately $25 \%$ failure rate has been observed in both $\mathrm{ACI}$ and micro-fracture in a randomised control clinical study after 5 years (Knutsen et al., 2007), which is expected to increase in longer follow up studies.

To overcome the afore mentioned constraints, researchers have started exploring the use of allogeneic cell sources such as foetal-derived stromal cells from placenta and umbilical cords which are young and immature, easily accessible, abundant and not associated to ethical concerns (Baksh et al., 2007; Fong et al., 2012). MSCs can be isolated from different compartments of the umbilical cord including Wharton's jelly (WJ), the perivascular region (PV), cord lining (CL), artery, and from the whole cord (MC, without separating each compartment) (Mennan et al., 2013; Subramanian et al., 2015). Like other adult MSCs, umbilical cord-derived stromal cells (UCSCs) have been shown to display high proliferative rate and multilineage differentiation potential (Mennan et al., 2013; Nirmal and Nair, 2013). They also express markers typical for MSCs, whilst being negative for haematopoietic, 
macrophage and endothelial cell markers. In addition, UCSCs are thought to have an immune privileged status and to exert immunosuppressive effects over different immune cell types in vitro, which makes them an attractive candidate for allogeneic based therapies (Subramanian et al., 2012; Troyer and Weiss, 2008).

The use of UCSCs for cartilage repair or cartilage tissue engineering have been studied to some extent in the past. Most available literature refers to the chondrogenic abilities displayed by MSCs collected from the blood compartment of cords; however, much less information is available on cells isolated from cord matrix or stroma (Park et al., 2015; Zhang et al., 2011). The intrinsic chondrogenic potential of MSCs isolated from the solid parts of umbilical cords has been studied mostly in vitro with divergent outcomes. While some studies are showing differentiation of UCSCs towards immature cartilage-forming cells (Wang et al., 2009a; Wang et al., 2009b), other studies argue poorer chondrogenic ability of UCSCs when compared with MSCs from other adult tissues (Bailey et al., 2007; Hildner et al., 2010; Mennan et al., 2013). In line with published original papers, many review articles also underscore several contradictory differences including multi-lineage potential and phenotypic profiles, which could be due to many factors, notably, isolation and handling techniques of MSCs in different laboratories, culture medium, scaffolds or cell carriers and use of various growth factors for chondrogenesis (El Omar et al., 2014; Troyer and Weiss, 2008). Of importance, many of the available studies are showing only qualitative outcomes and provide insufficient evidence for expression of cartilage tissue signature genes and proteins quantitatively, or the development of tissuelike structures that clearly resemble cartilage.

In our study, we aim to shed some light on this still uncertain topic by studying the chondrogenic potential of UCSCs-MC isolated from whole cords. Here we have used multiple quantitative approaches for measuring cartilage genes and proteins. Chondrogenic potency has been investigated by exposing cells to multiple combinations of growth factors, including co-culture trials with cartilage explants, and the outcomes have been compared with MSCs collected from different sources. Our data revealed intriguing differences in chondrogenic potential among different MSCs. Of note, UCSCs-MC are found to have poor differentiation ability towards the chondrogenic lineage in vitro when compared to Hoffa's fat pad derived stromal cells (HFPSCs), synovial membrane derived stromal cells (SMSCs) and articular chondrocytes (ACs).

\section{Materials and Methods}

\section{Human Material}

All human samples were collected from the University Hospital Northern Norway (UNN) with patients' informed consent, and the Regional Ethical Committee (REK Nord) at the University of Tromsø approved the study. Human ACs, SMSCs and HFPSCs were isolated from the knee joints of three patients aged 45 to 60 years undergoing total knee replacement. UCSCs-MC were isolated from three umbilical cords collected immediately after birth and processed within $3 \mathrm{~h}$ of collection.

\section{Isolation and culture of UCSCs-MC, HFPSCs, SMSCs and ACs}

All cell types were isolated using a mixed enzymaticexplant method in which tissue sections were minced and digested in collagenase XI solution (Cat. no. C9407; Sigma Aldrich) at a final concentration of $1.25 \mathrm{mg} / \mathrm{mL}$ on a shaker at $37^{\circ} \mathrm{C}$. Isolation of UCSCs-MC was conducted as previously described with minor modifications (Mennan et al., 2013). Briefly, whole cord was washed three times with sterile Dulbecco's phosphate buffered saline (DPBS; Cat. no. D8537; Sigma-Aldrich) to remove blood, followed by immersion in $90 \%$ ethanol for $30 \mathrm{~s}$ and immediately washed and stored in DPBS for immediate use. Approximately $2 \mathrm{~cm}$ sections of whole cord were cut into small pieces, and further subjected to enzyme digestion for $1.5 \mathrm{~h}$ at a concentration previously indicated. During knee replacement operations, pieces of synovium were collected and the membrane fraction (synovial membrane) was carefully separated from the fat tissues (Hoffa's fat pad). HFP and SM tissues were washed three times with DPBS, followed by cutting into small pieces prior to enzymatic digestion for $1.5 \mathrm{~h}$. On the other hand, cartilage biopsies were washed in DPBS and minced carefully into $1-1.5 \mathrm{~mm}^{3}$ pieces to avoid any bone fraction with the biopsies, prior to enzymatic digestion for $4 \mathrm{~h}$ at a concentration previously indicated.

Partially digested tissues were centrifuged for $10 \mathrm{~min}$ at $800 \times g$ and re-suspended in high glucose Dulbecco's Modified Eagle Medium (DMEM; Cat. no. D5796; SigmaAldrich) supplemented with L-ascorbic acid (62 mg/L) (Cat. no.103033E; BDH Laboratory), penicillin and streptomycin (1\%) (P/S; Cat. no. P4333; Sigma-Aldrich) and $20 \%$ foetal bovine serum (FBS; Cat. no. S0115; Biochrom) and subsequently, plated in $75 \mathrm{~cm}^{2}$ culture flasks (Cat. no. 156499; Thermo Scientific) at $37{ }^{\circ} \mathrm{C}$ in humidified atmosphere containing $5 \% \mathrm{CO}_{2}$. Partially digested cartilage allowed more cells to attach to the culture flask. For isolation of HFPSCs, only the pelleted fraction of cells were collected after centrifugation, whereas the fat layer on top was discarded. After cell attachment, cultures of UCSCs-MC, HFPSCs and SMSCs were expanded in high glucose DMEM supplemented with $10 \% \mathrm{FBS}$ and basic fibroblast growth factor $(25 \mathrm{ng} / \mathrm{mL})$ (bFGF; Cat. no. 100-18C; Peprotech), whereas de-differentiated ACs were expanded with only $10 \%$ FBS as medium supplement. Primary cultures were further expanded in monolayers, followed by dissociation from culture flasks using PBS based enzyme-free dissociation solution (Cat. no. S-014-B; Merck Millipore) and plated in $175 \mathrm{~cm}^{2}$ culture flasks (Cat. no. 159910; Thermo Scientific). Medium was changed every 3 to $4 \mathrm{~d}$, and the cells were used for experimentation at passage 3-4, which correspond to 6-8 cumulative population doublings, measured by direct cell counting.

Immunoprofiling of stromal cells by flow cytometry Expression of cell surface molecules from cultured UCSCs-MC, HFPSCs and SMSCs on the third passages 
were analysed by flow cytometry using the BD stemflow hMSC analysis kit (Cat. no. 562245; BD Biosciences) following the manufacturer's instructions. Briefly, cells from each tissue source were harvested and pelleted at $400 \times g$ for $3 \mathrm{~min}$ at $4{ }^{\circ} \mathrm{C}$. The pellet was washed three times with cold stain buffer (Cat. no. 554656; BD Biosciences), filtered through a cell strainer $(70 \mu \mathrm{m})$ and re-suspended in cold stain buffer to a concentration of $5 \times 10^{6}$ cells $/ \mathrm{mL}$. Cells were incubated with directly conjugated antibodies against classical MSCs characterisation markers described by the International Society for Cellular Therapy (ISCT) (Dominici et al., 2006). In addition, antibodies for CD44, CD106, CD146, CD166, and CD271 cell surface markers and appropriate isotype control antibodies (BD Biosciences, USA) were used in the analysis. Samples were analysed using a BD FACSAria flow cytometer and FlowJo software (Tree Star Inc., USA).

\section{D cell culture and induction of chondrogenesis}

Chondrogenic differentiation potential of all cell sources used in this study was done using the pellet system as described previously with few modifications (Ivascu and Kubbies, 2006). Confluent cell cultures at passage 3-4 were harvested and re-suspended in high glucose DMEM supplemented with L-ascorbic acid (62 mg/L), P/S (1 \%), $10 \% \mathrm{FBS}$ and bFGF $(25 \mathrm{ng} / \mathrm{mL})$. A volume of $150 \mu \mathrm{L}$ containing $5 \times 10^{4}$ cells was transferred to each well of a poly-HEMA (Cat. no. P3932; Sigma-Aldrich) coated conical-bottom 96-well culture plate (Cat. no. 249935; Thermo Scientific). Plates were centrifuged for $10 \mathrm{~min}$ at $1100 \times g$ to form aggregates, and then transferred into a low oxygen atmosphere incubator set up at $5 \% \mathrm{CO}_{2}, 3 \% \mathrm{O}_{2}$ and $37^{\circ} \mathrm{C}$. After $48 \mathrm{~h}$, spheroids were collected and transferred to a 24-well ultra-low attachment cell culture plate (Cat. no. 3473; Corning) containing $1 \mathrm{~mL}$ of complete chondrogenic medium per well (8-10 spheroids/well). Spheroids were cultured in different serum-free chondrogenic media for three weeks at low oxygen $\left(3 \% \mathrm{O}_{2}\right)$, and half of the medium was changed with fresh chondrogenic medium twice a week.

\section{Chondrogenic media}

Basal chondrogenic medium was composed of high glucose DMEM, L-ascorbic acid (62 mg/L), P/S (1 \%), dexamethasone (1 $\mu \mathrm{g} / \mathrm{mL})$ (Cat. no. PZN-3103491; Galenpharma), Insulin-transferrin-selenium supplement (ITS) (1:1000) (Cat. no. 354351; BD Biosciences) (Tang et al., 2015). Five different anabolic growth factors were used to induce chondrogenesis in $3 \mathrm{D}$ cultures. These include transforming growth factor $\beta 1$ (10 ng/mL) (TGF- $\beta 1$; Cat. no. $100-21 \mathrm{C})$, transforming growth factor $\beta 3(10 \mathrm{ng} / \mathrm{mL})$ (TGF- $\beta 3$; Cat. no. 100-36E), bone morphogenic protein 2 (100 ng/mL) (BMP-2; Cat. no. 120-02C), insulin like growth factor $1(20 \mathrm{ng} / \mathrm{mL})(\mathrm{IGF}-1$; Cat. no. 100-11) and bone morphogenic protein 7 (100 ng/mL) (BMP-7; Cat. no. 120-03). All growth factors were purchased from Peprotech, UK. Three dimensional cell aggregates were grown in complete chondrogenic medium consisting of basal chondrogenic medium supplemented with one of the six different combination of growth factors: 1$)$ TGF- $\beta 1$ + IGF-1; 2) TGF- $\beta 1$ + BMP-2; 3 ) TGF- $\beta 1$ + BMP-7; 4)
TGF- $\beta 3+$ IGF-1; 5) TGF- $\beta 3$ + BMP-2 and 6) TGF- $\beta 3$ + BMP-7.

\section{Chondrogenesis of UCSCs-MC in co-culture with cartilage explants and cultured synovial cells}

Co-culture experiments were carried out using $0.4 \mu \mathrm{m}$ transwell inserts (Cat. no. 3413; Corning) and the best growth factor mixture to induce chondrogenesis among the six different conditions tested. On one hand, fresh cartilage biopsies were washed three times with sterile DPBS and minced into $1-1.5 \mathrm{~mm}^{3}$ pieces. The minced cartilage pieces were transferred to ultra-low attachment 24-well cell culture plates containing complete chondrogenic medium supplemented with TGF- $\beta 3+$ BMP-2 (Fig. 10a). On the other hand, synovial cells, consisting of a mixed culture of primary HFPSCs and SMSCs (1:1) were seeded at a density of $2 \times 10^{4}$ cells in 24 -well cell culture plates (Cat. no. 353047 ; BD Falcon) containing complete chondrogenic medium supplemented with TGF- $\beta 3+$ BMP-2 (Fig. 10b). On the top chamber, four or five UCSCs-MC spheroids collected $48 \mathrm{~h}$ after initial cell aggregation were placed in each insert and incubated in separated co-culture during three weeks (see diagram in Fig. 10a,b) at low oxygen $\left(3 \% \mathrm{O}_{2}\right)$, and half of the medium was changed with fresh chondrogenic medium twice a week.

\section{Histology and immunohistochemistry}

Spheroids from all cell sources were harvested after three weeks incubation, washed three times with ice cold DPBS and fixed in $4 \%$ formalin overnight. Fixed spheroids were washed with DPBS embedded in agarose blocks $(1 \%)$ and transferred into paraffin. Paraffin embedded sections $(4 \mu \mathrm{m})$ were heated at $60{ }^{\circ} \mathrm{C}$ for $30-60 \mathrm{~min}$ prior to de-waxing and immersing in xylene twice for $10 \mathrm{~min}$ and rehydrated in a series of ethanol washes followed by washing twice in water for $3 \mathrm{~min}$ each. Sections were stained with Alcian blue solution (Cat. no. A5268; SigmaAldrich) for $30 \mathrm{~min}$ followed by washing in distilled water for $2 \mathrm{~min}$ and counter stained with nuclear fast red solution (Cat. no. N3020; Sigma-Aldrich) for $5 \mathrm{~min}$, ending by washing in distilled water for $2 \mathrm{~min}$. The sections were dehydrated in a series of ethanol wash followed by cleaning in xylene twice and a cover slip with Histokit (Cat. no. 1025/500; Glaswarenfabrik Karl Hect) mounted over stained sections. The image was analysed using bright field light microscopy for metachromatic staining of proteoglycans with Alcian blue.

For immunostaining of collagen type II and type I, rehydrated paraffin sections were treated with hyaluronidase ( $2 \mathrm{mg} / \mathrm{mL}$ ) (Cat. no. H3506; Sigma-Aldrich) and pronase (1 mg/mL) (Cat. no. 10165921001; Roche) for $15 \mathrm{~min}$ and $30 \mathrm{~min}$, respectively at $37^{\circ} \mathrm{C}$ for antigen retrieval. The slides were then rinsed in distilled water followed by blocking with $2 \%$ BSA for $10 \mathrm{~min}$, prior to overnight incubation at $4{ }^{\circ} \mathrm{C}$ using rabbit antihuman collagen type II antibody (Cat. no. T59104R; Meridian Life Science) and rabbit antihuman collagen type I antibody (Cat. no. LS-B3653; LifeSpan Biosciences) at a dilution of 1:100 and 1:500 respectively. The sections were treated with peroxidase block solution for $5 \mathrm{~min}$, followed by rinsing with distilled water. The slides were then wiped gently 
Table 1. Scoring categories for histological evaluation of chondrogenesis of Alcian blue stained spheroids.

\begin{tabular}{|l|c|}
\hline \multicolumn{1}{|c|}{ Scoring Categories } & Score \\
\hline 1. Uniformity and intensity of Alcian blye stain & \\
\hline No stain & 0 \\
\hline Weak stain of matrix & 1 \\
\hline Moderate stain & 2 \\
\hline Strong stain of matrix & 3 \\
\hline 2. Matrix formation based on proteoglycan staining & 0 \\
\hline No matrix formation & 1 \\
\hline Little matrix formation with high cell density & 2 \\
\hline Moderate matrix formation with relatively low cell density & 3 \\
\hline High matrix formation with low cell density & \\
\hline 3. Cell morphology & 0 \\
\hline Highly condensed and elongated cells & 1 \\
\hline Less condensed and elongated/rounded cells & 2 \\
\hline Mixed elongated/rounded cells with lacunae & 3 \\
\hline Rounded Cells with Lacunae/cartilage morphology & \\
\hline
\end{tabular}

and incubated with peroxidase labelled polymer-HRP (Cat. no. K4010; Dako) for 30 min followed by washing three times with PBS. The sections were incubated with diaminobenzidine (DAB) chromogen and substrate-buffer solution (1 drop of DAB $+1 \mathrm{~mL}$ of substrate-buffer) (Cat. no. K4010; Dako) for 5-10 min, followed by rinsing off with distilled water. Sections were then counterstained with haematoxylin (Cat. no. RBA-4213-00A; Cell Path) for $45 \mathrm{~s}$ followed by washing with distilled water and incubation in Scotts solution for 20 s. Finally, sections were dehydrated and mounted with Histokitt.

\section{Quantitative analysis of histology}

We have used "The Bern Score" with a few modifications as a semi-quantitative scoring method to evaluate the chondrogenicity of 3D spheroids, based on the staining of matrix proteoglycans with Alcian blue (Grogan et al., 2006). The Bern score evaluates the cartilage formation by three categories and each of the categories have a scoring range from 0 to 3 with an overall score of 9 for each spheroid (Table 1).

\section{Biochemical analysis of GAGs}

Spheroids from ACs and UCSCs-MC were subjected to biochemical analysis to determine the GAG (glycosaminoglycan) and DNA content. Spheroids were harvested after three weeks in chondrogenic conditions and washed with PBS three times followed by digestion with papain $(125 \mu \mathrm{g} / \mathrm{mL})$ (Cat. no. P3125; SigmaAldrich) buffer for $18-24 \mathrm{~h}$ at $65{ }^{\circ} \mathrm{C}$. Papain digested samples were centrifuged at $16,000 \times g$ for $10 \mathrm{~min}$ and supernatants were used immediately or stored at $-70{ }^{\circ} \mathrm{C}$ for biochemical analysis. Sulphated-GAG content was measured spectrophotometrically at $655 \mathrm{~nm}$ by 1,9 dimethylmethylene blue dye assay using the Blyscan s-GAG assay kit (Cat. no. B1000; Biocolor). In addition, DNA was measured using Quant-iT PicoGreen dsDNA Assay Kit (Cat. no. P7589; Life Technologies) as described previously (Toh and Cao, 2014). Fluorescence readings were taken using the CLARIOstar microplate reader (BMG LABTECH, Germany) with excitation and emission at $485 \mathrm{~nm}$ and $535 \mathrm{~nm}$, respectively. The amount of s-GAG content was normalised to DNA content for each sample.

\section{Transmission electron microscopy}

Spheroids were harvested after three weeks and processed as previously described (Meknas et al., 2012). Briefly, spheroids were fixed in McDowell's fixative (McDowell and Trump, 1976) overnight followed by post-fixation in $1 \% \mathrm{OsO}_{4}$ for $1 \mathrm{~h}$. Samples were stained en bloc in $2 \%$ uranyl acetate prior to dehydration in a graded series of ethanol washes and embedded in Epon according to standard procedure. Sections were cut on a Leica Ultracut $\mathrm{S}$ (Vienna, Austria) with a diamond knife from Diatome (Switzerland). Micrographs were taken using a JEOL 1010 (Tokyo, Japan) electron microscope with a Morada camera system (Olympus Soft Imaging Systems, Germany).

\section{Stemness-related transcriptional factors (SRTF) gene expression analysis}

RNA from monolayer cultures was extracted using the Perfect Pure RNA Cultured Cell Kit (Cat. no. 2900319; 5 prime) according to the manufacturer's instructions. RNA from spheroid cultures was extracted using the RNeasy ${ }^{\circledR}$ Micro Kit (Cat. no. 74004; Qiagen). In brief, the spheroids were harvested into $2 \mathrm{~mL}$ PCR clean tubes containing one stainless steel ball (Cat. no. 69989; Qiagen), washed once with PBS before disruption in buffer RLT in a Qiagen TissueLyser machine (Retch) and homogenisation using QiaShredder columns (Cat. no. 79654; Qiagen). RNA was cleaned using MinElute columns including on-column DNase digestion. Concentration was measured using spectrophotometry (Nano Drop ND-1000), and samples were diluted to a final concentration of $8.25 \mathrm{ng} / \mathrm{L}$ before reverse transcription using the qScript cDNA Synthesis Kit (Cat. no. 95047; Quanta Biosciences) according to the manufacturer's protocol. Specific primers for stemness-related transcriptional factors (Drela et al., 
Table 2. Primers used for RT-PCR.

\begin{tabular}{|l|l|l|}
\hline \multirow{2}{*}{ Gene } & Product size & Primer sequence \\
\hline \multirow{2}{*}{ OCT3/4A } & \multirow{2}{*}{$144 \mathrm{bp}$} & Forward: 5'-GCA GAG GGA TAC GCC CTA AGT-3' \\
\cline { 3 - 3 } & \multirow{2}{*}{ SOX2 } & Reverse: 5'-CAA GAG TAC AGC CAT GAT TCC AAA-3' \\
\hline \multirow{2}{*}{ NANOG } & \multirow{2}{*}{$148 \mathrm{bp}$} & Forward: 5'-ACA CCA ATC CCA TCC ACA CT-3' \\
\cline { 3 - 3 } & Reverse: 5'-GCA AAC TTC CTG CAA AGC TC-3' \\
\cline { 3 - 3 } & \multirow{2}{*}{ APRT } & Rorward: 5'-AAT ACC TCA GCC TCC AGC AGA TG-3' \\
\cline { 3 - 3 } & \multirow{2}{*}{$300 \mathrm{bp}$} & Forward: 5'-CCC GAG GCT TCC TCT TTG GC-3' \\
\cline { 3 - 3 } & & Reverse: 5'-CTC CCT GCC CTT AAG CGA GG-3' \\
\hline
\end{tabular}

Table 3. Hydrolysis probes.

\begin{tabular}{|l|l|l|}
\hline Gene name & Gene symbol & Assay ID \\
\hline Collagen, type I, alpha 1 & COL1A1 & Hs00164004_m1 \\
\hline Collagen, type II, alpha 1 & COL2A1 & Hs00264051_m1 \\
\hline Collagen, type IX, alpha 1 & COL9A1 & Hs00932129_m1 \\
\hline Collagen, type X, alpha 1 & COL10A1 & Hs00166657_m1 \\
\hline Versican & VCAN & Hs00171642_m1 \\
\hline Aggrecan & ACAN & Hs00153936_m1 \\
\hline SRY(sex determining region Y)-box 9 & SOX9 & Hs00165814_m1 \\
\hline Tyrosine 3-monooxygenase/tryptophan 5-monooxygenase activating protein, zeta & YWHAZ & Hs00237047_m1 \\
\hline
\end{tabular}

2014) were ordered from Invitrogen (Table 2). Adenine phosporibosyltransferase (APRT) was included for RNA quality control as an $800 \mathrm{bp}$ product would yield in the case of contaminating DNA. The RT-PCR reaction mix comprised of $12.5 \mu \mathrm{L}$ JumpStart ${ }^{\mathrm{TM}}$ REDTaq $^{\circledR}$ ReadyMix $^{\circledR}$ Reaction Mix, $0.5 \mu \mathrm{L}$ forward primer $(20 \mathrm{nM}), 0.5 \mu \mathrm{L}$

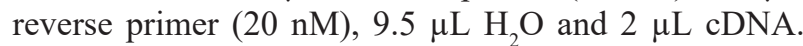
The $25 \mu \mathrm{L}$ reaction was run on a MJ Research PTC-200 thermal cycler using the following conditions: initial denaturation for $2 \mathrm{~min}$ at $94{ }^{\circ} \mathrm{C} ; 35$ cycles of $30 \mathrm{~s}$ at $94{ }^{\circ} \mathrm{C}$, $30 \mathrm{~s}$ at $58^{\circ} \mathrm{C}$ and $2 \mathrm{~min}$ at $72{ }^{\circ} \mathrm{C}$; final extension for $5 \mathrm{~min}$ at $72{ }^{\circ} \mathrm{C}$. Products were separated on a FlashGel (Cat. no. 57023; Lonza) and photographed using the ImageQuant LAS4000 system.

\section{Cartilage specific gene expression analysis}

Quantitative (qPCR) reactions were performed for spheroids culture on StepOnePlus Real-Time PCR detection system (Applied Biosystems). The relative quantification experiment was run with hydrolysis probes targeting cartilage signature genes (Table 3, Life Technologies). Based on validation experiments YWHAZ alone proved as the most stable reference gene. The reaction volume of $10 \mu \mathrm{L}$ included $5 \mu \mathrm{L}$ TaqMan Fast Universal PCR Mastermix No AmpErase UNG (Cat. no. 4366072; Applied Biosystems), $2.5 \mu \mathrm{L}$ water, $2 \mu \mathrm{L}$ cDNA and $0.5 \mu \mathrm{L}$ of the respective assays. Three technical replicates of each sample were applied to a MicroAmp Fast Optical 96-well reaction plate (Cat. no. 4346906; Applied Biosystems), and water and no-RT samples were added for the negative control. The plates were run on a StepOnePlus (Applied Biosystems), using the following cycling conditions: hold at $95^{\circ} \mathrm{C}$ for $20 \mathrm{~s}, 40$ cycles at $95^{\circ} \mathrm{C}$ for $1 \mathrm{~s}$ and then at $60^{\circ} \mathrm{C}$ for $20 \mathrm{~s}$. Expression relative to chondrocyte spheroids was calculated using the delta delta $\mathrm{Cq}$ method and $95 \%$ confidence intervals were generated in Excel.

\section{Statistical analysis}

For the biochemical analysis, the Student's $t$-test was used to compare the mean differences between experimental and control groups (three different biological replicates per group). The result was expressed as mean $\pm \mathrm{SD}$ and values of $p<0.05$ were considered as statistically significant. In addition, for histological scoring, the Kruskal-Wallis was used followed by post hoc Bonferroni correction with Mann-Whitney U comparisons for statistical analysis using IBM SPSS statistics 22 (Chicago, USA). Values of $p<0.05$ were considered as statistically significant. Last, for gene expression analysis, relative gene expression normalised to ACs was shown as $95 \%$ confidence intervals using Microsoft Excel.

\section{Results}

\section{Outcomes of cell isolation and features of cell growth in monolayers}

Cells with fibroblastic appearance were successfully isolated from all four tissues sources. Isolated cells from umbilical cords, Hoffa's fat pads and synovial membranes were adherent to plastic and had colony-forming abilities. For umbilical cord tissue, cells normally took 5-10 d to attach to the culture plate, and the yield of cells after initial cell seeding was relatively low. In primary cultures, UCSCs-MC cultures presented a heterogeneous morphology and had a slow growing rate, taking 15-20 d to reach confluence (Fig. 1b). However, after first subculturing, UCSCs-MC acquired a more homogeneous 

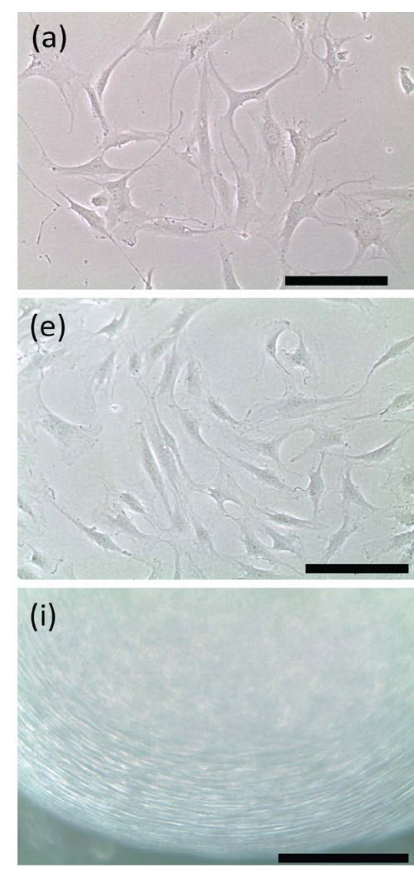
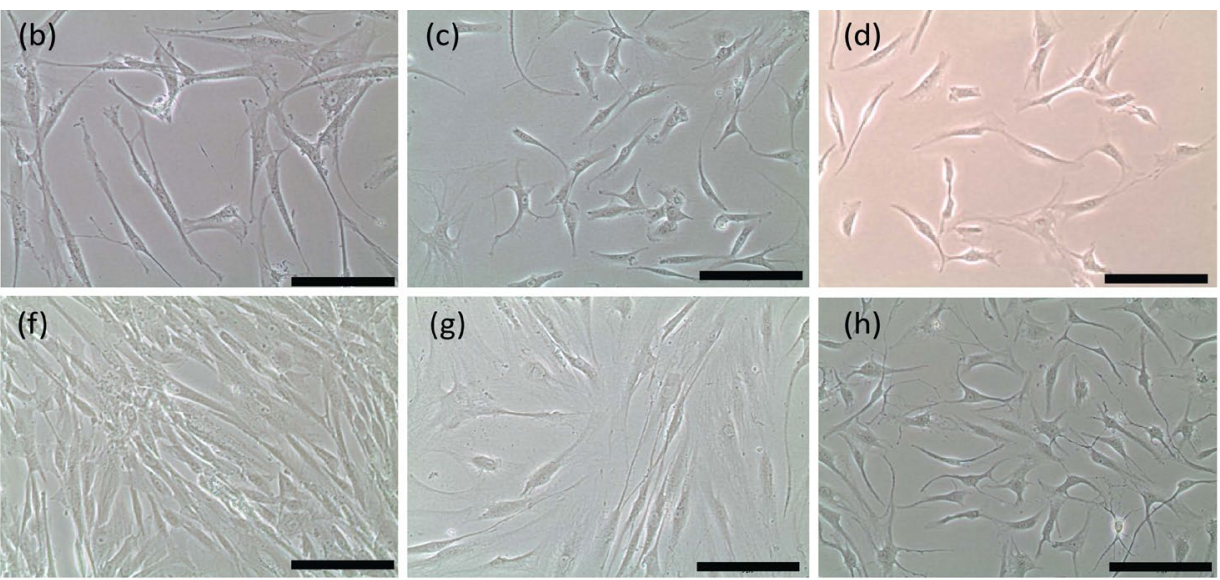

(j)
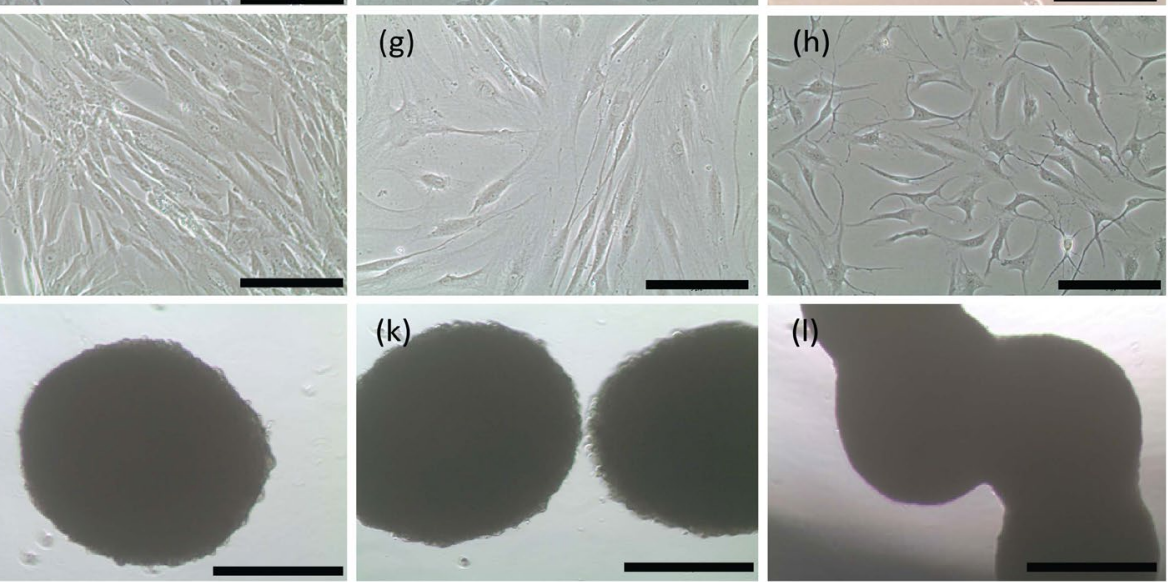

Fig. 1. Light microscopy images of different stages of cell culture and in 3D spheroids. (a-d) Monolayer culture of (a) ACs, (b) UCSCs-MC, (c) HFPSCs and (d) SMSCs after first plating. Scale bar: $5 \mu \mathrm{m}$. (e-h) Confluent culture of (e) ACs, (f) UCSCs-MC, (g) HFPSCs and (h) SMSCs. Scale bar: $5 \mu \mathrm{m}$. In the lower row (i-l), 3D Cell culture of UCSCs-MC in micro-aggregates to induce chondrogenesis: (i) 50,000 cells after initial centrifugation in conical bottom wells, (j) single UCSCs-MC spheroid after 1 week, (k) UCSCs-MC spheroids prior to fuse after 1 week and (l) fused spheroids after 2 weeks in 3D culture. Scale bar: $500 \mu \mathrm{m}$.

morphology and higher proliferation rate (Fig. 1f). In contrast, isolated HFPSCs and SMSCs contained a high number of adherent MSC-like cells, which attached to the culture plate during the first 3-5 d (Fig. 1c,d). In addition, HFPSCs and SMSCs grew initially faster than UCSCs-MC, reaching $100 \%$ confluence in 10-14 d in $75 \mathrm{~cm}^{2}$ culture flasks (Fig. 1g,h). Unlike stromal cells, chondrocytes attached to plastic faster (2-4 d) but grew at a slower rate (18-25 d to reach confluence). In addition, the de-differentiated chondrocytes looked less elongated and more polygonal than the mesenchymal cells from the other sources (Fig. 1a). In 3D conditions, one week after cell aggregation, spheroids from all cell sources looked similar, displaying a perfectly round and compact morphology with sharp edges (Fig. 1j-I)). However, sometimes spheroids from all cell sources had fused with others after 2-3 weeks and turned into a larger structure (Fig. 1i-l).

\section{Mesenchymal stromal cell phenotypic characterisation}

Immunophenotypic characterisation of cells using flow cytometry demonstrated that UCSCs-MC, HFPSCs and SMSCs remained positive for classical mesenchymal markers such as CD73, CD90 and CD105, with expression levels above $99 \%$. In contrast, the same cells lacked expression for haematopoietic, macrophage and endothelial markers i.e. CD11b, CD19, CD34, CD45 and HLA-DR (Fig. 2a). In this study, we wanted to further investigate the phenotype of isolated MSCs for additional cell surface markers related to cell differentiation potential (Fig. 2b). Hence, it has been shown that subpopulations of MSCs may express cell surface markers which could predict differentiation potential towards a chondrogenic lineage (Arufe et al., 2010; Baksh et al., 2007; Maleki et al., 2014; Pretzel et al., 2011) including CD44, also called homing cell adhesion molecule (hyaluronate receptor), CD106 or vascular cell adhesion molecule (VCAM-1), CD146 or melanoma cell adhesion molecule (MCAM), CD166 or activated leukocyte cell adhesion molecule (ALCAM), and CD271 also named low-affinity nerve growth factor receptor. In this study, CD44 was expressed in $99 \%$ of the population in the three MSCs, whereas none of the cell types expressed CD106 and CD271. Furthermore, UCSCs-MC showed positivity for both CD146 and CD166 with expression levels above $90 \%$. However, a subtle difference in expression of CD146 was observed among the three cell types. Whereas UCSCs-MC cultures showed a uniform positivity for CD146, HFPSCs and SMSCs showed two distinct populations, indicating the existence of a subgroup of cells in the cultures that were negative for this marker (Fig. 2b).

\section{Chondrogenic potential of ACs, UCSCs-MC, HFPSCs and SMSCs in 3D cultures}

Chondrogenic potential of UCSCs-MC and other cell sources was tested in scaffold-free 3D cultures originated by cell condensation or pellets. To take a more unbiased approach, chondrogenesis of all cell types was tested under the influence of different mixtures of growth factors (GF). Metachromatic staining with Alcian blue was used for early screening of spheroids in different chondrogenic medium, and the best growth factors combinations were used to 

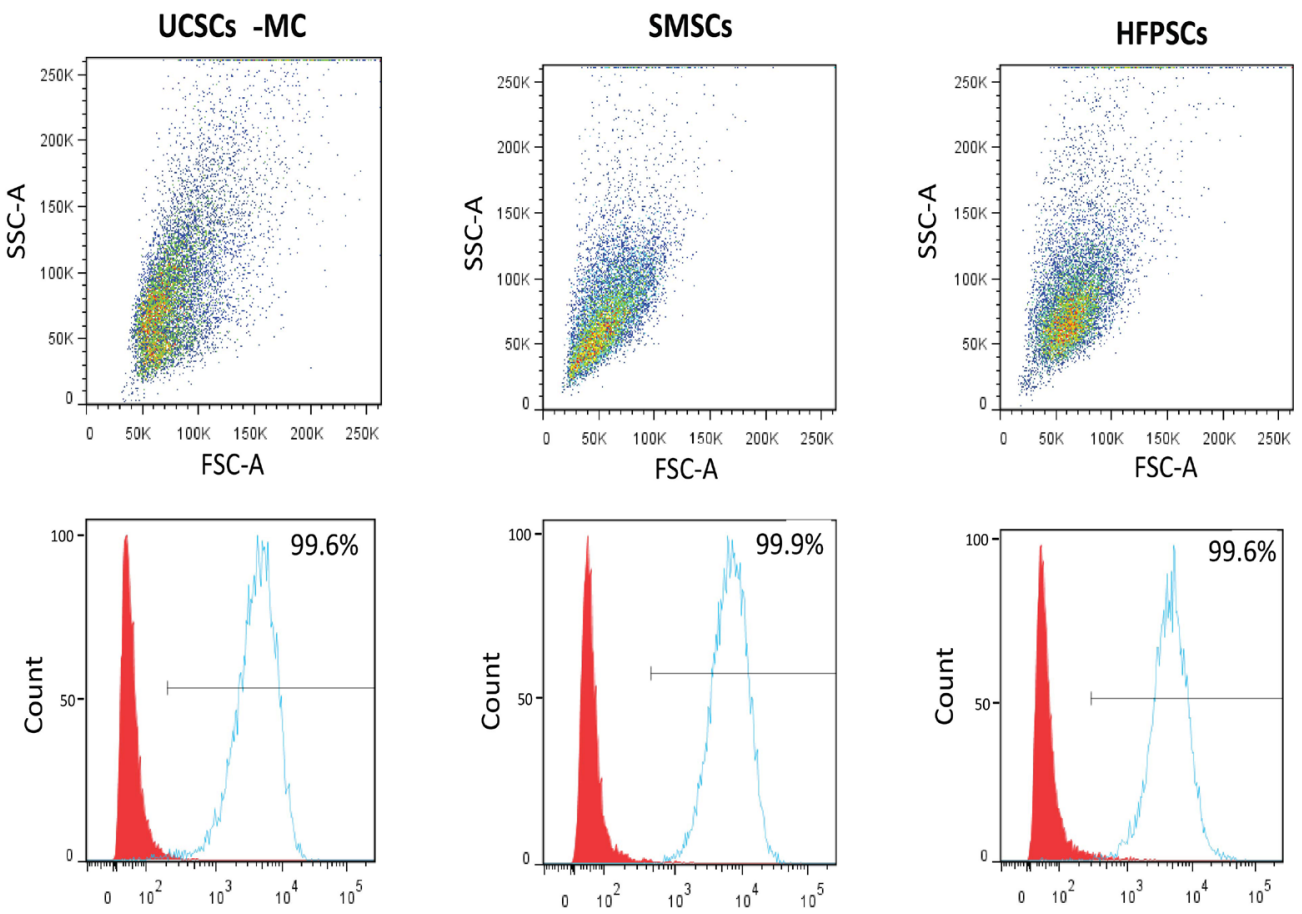

CD105
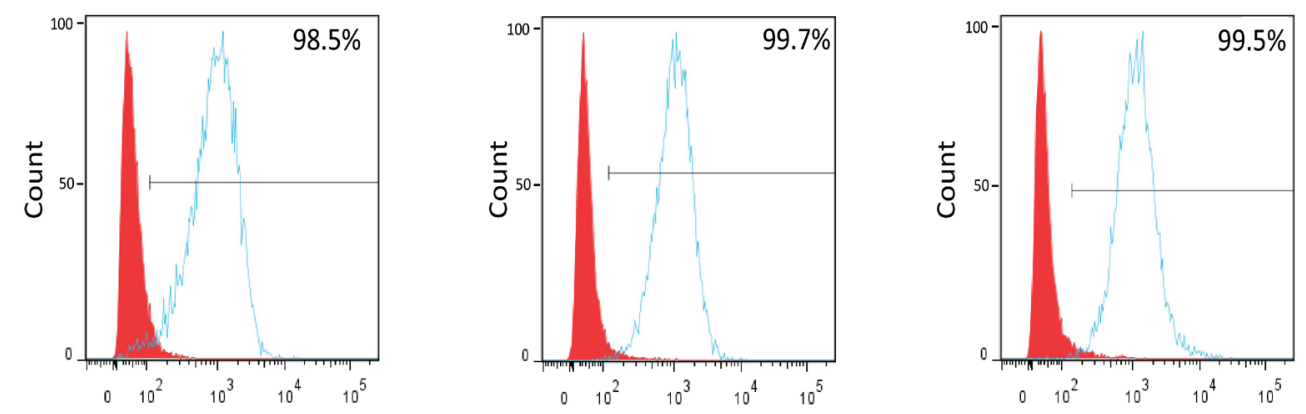

CD73
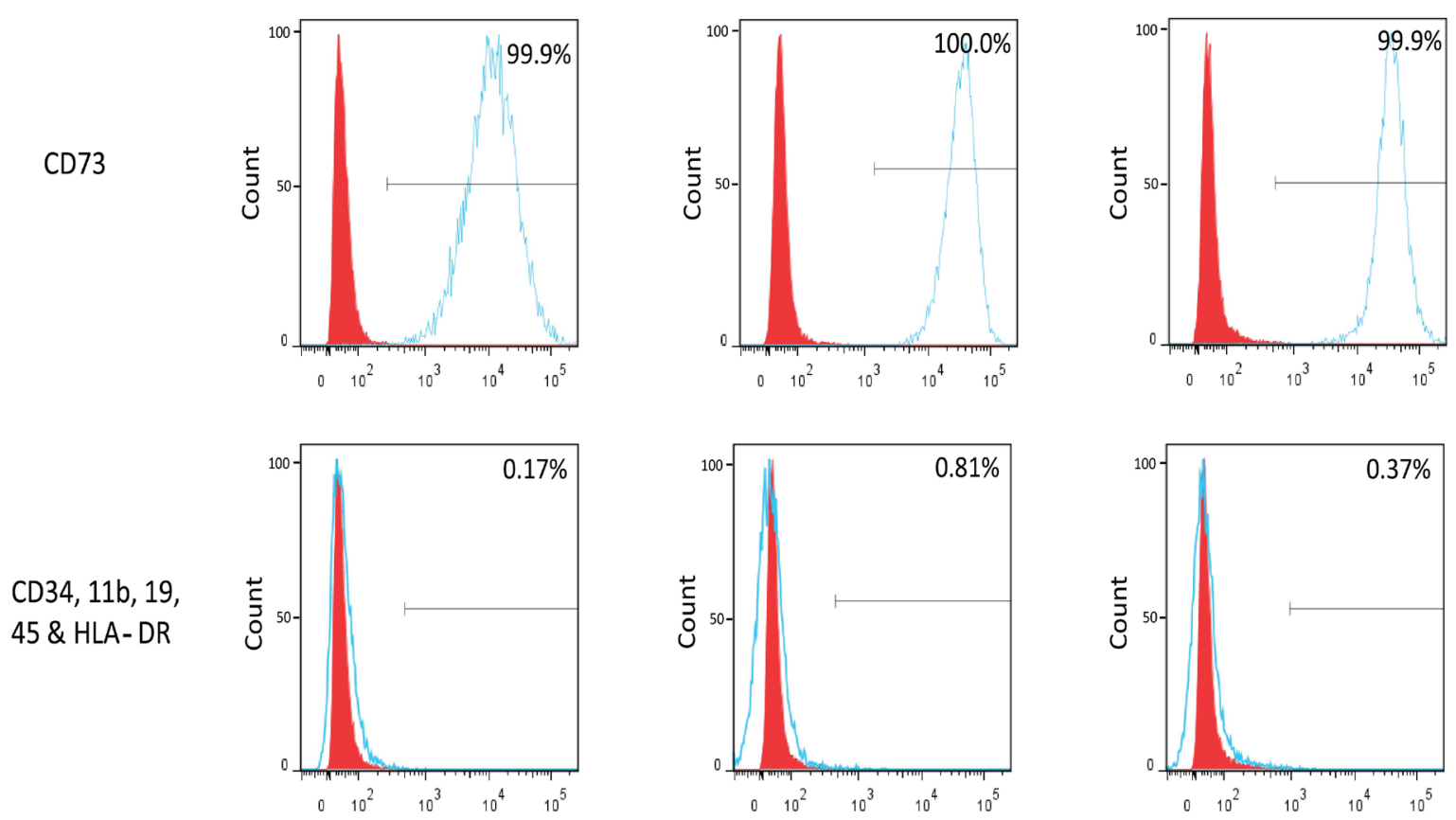

Fig. 2a. Characterisation for stromal cell-like phenotype by flow cytometry. Cells in passage 3 were prepared from the three different tissue sources, stained with specific cell surface markers and analysed by flow cytometry. The classical set of positive and negative markers characteristic for mesenchymal stromal cells following requirements from the International Society for Cellular Therapy (ISCT). Red peaks represent the isotype control and blue peaks represent the tested markers. 
UCSCs -MC
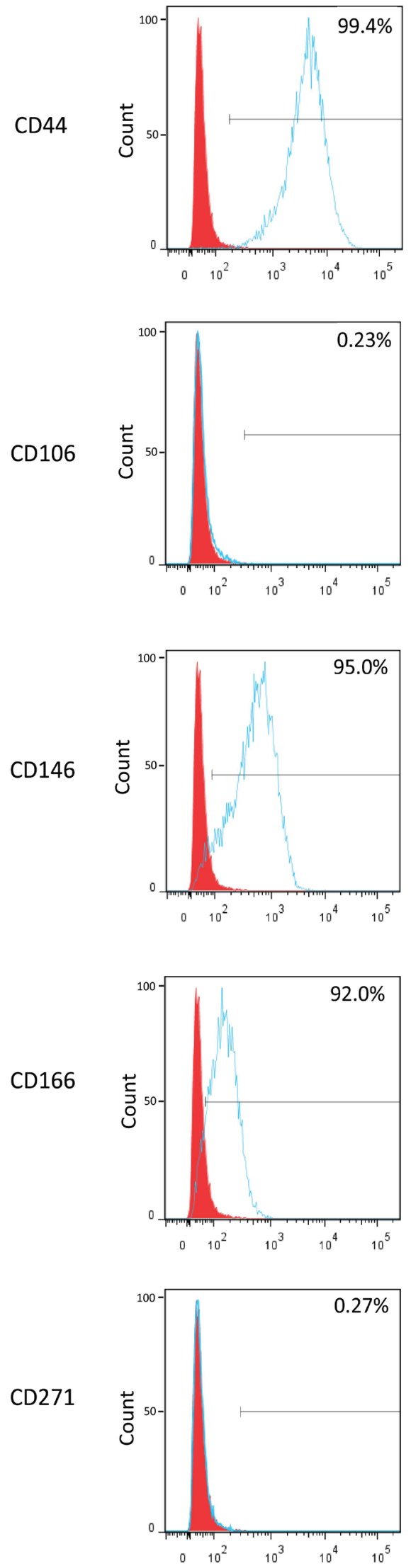

SMSCs
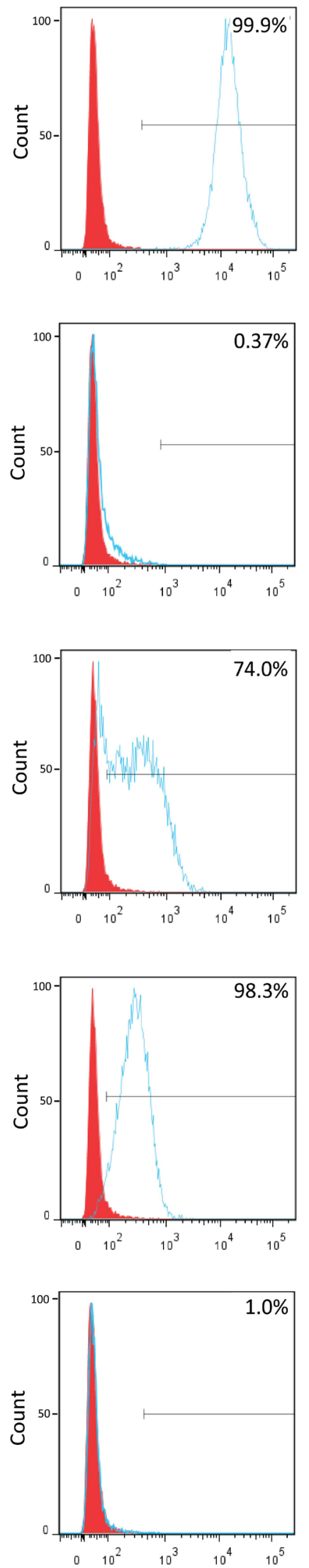

HFPSCs
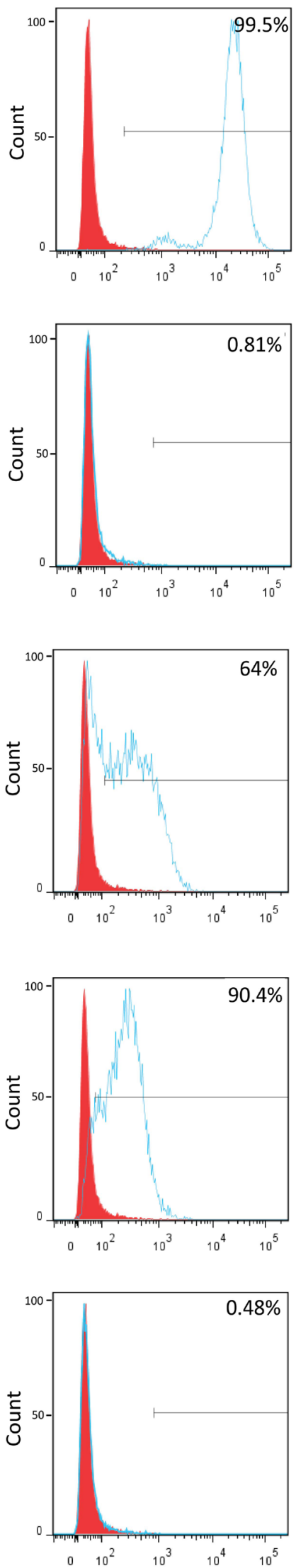

Fig. 2b. Characterisation for stromal cell-like phenotype by flow cytometry. Cells in passage 3 were prepared from the three different tissue sources, stained with specific cell surface markers and analysed by flow cytometry. Additional cell surface markers related to stromal cells differentiation potential. Red peaks represent the isotype control and blue peaks represent the tested markers. 

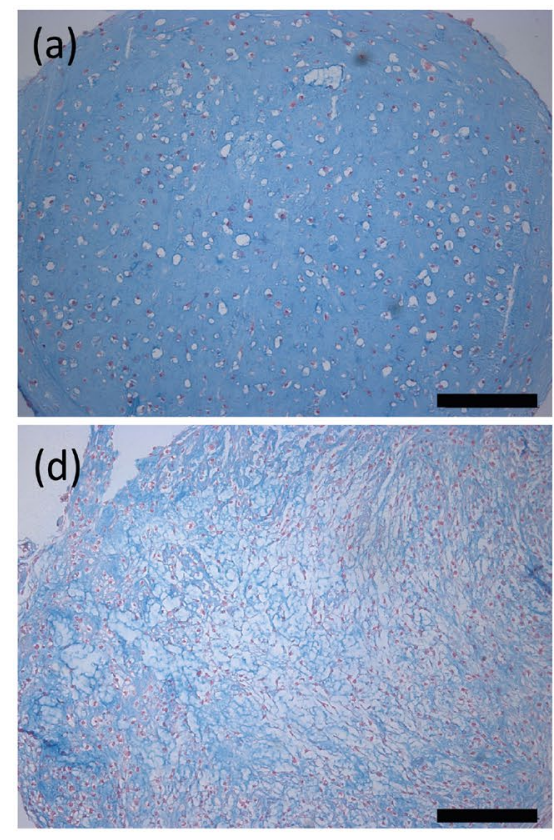

UCSCs-MC
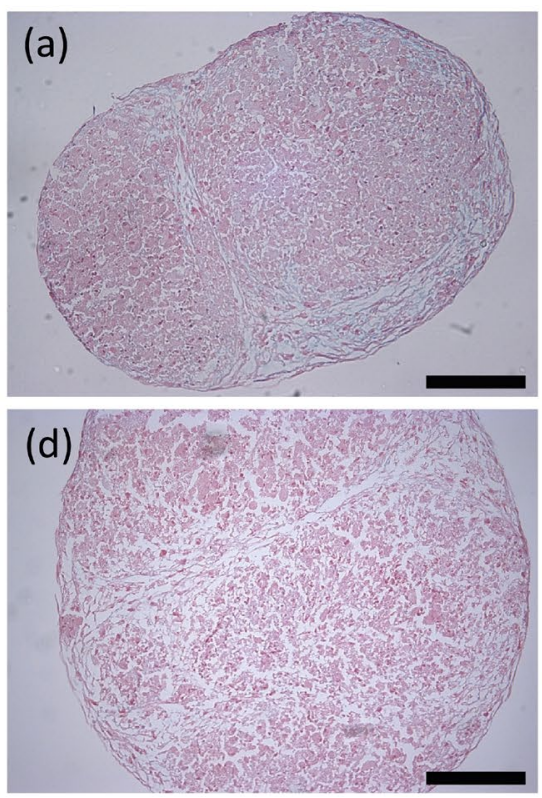

ACs
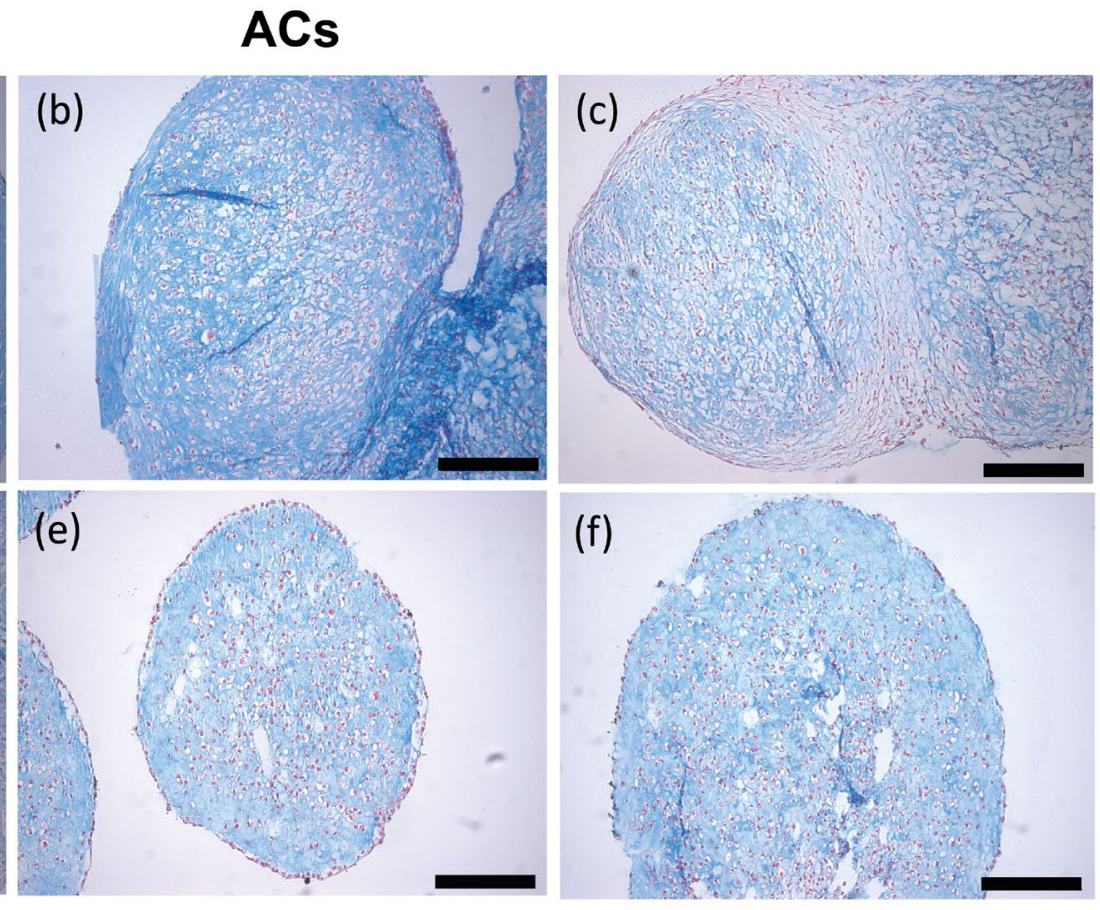

Fig. 3. Chondrogenesis of ACs and UCSCs-MC in 3D spheroids exposed to different cocktails of growth factors. Images show bright light microscopy of thin sections from UCSCs-MC spheroids stained for proteoglycans with Alcian blue, and the nuclei counterstained with Sirius red. (a) Condition TGF- $\beta 1+B M P-2$, (b) condition TGF- $\beta 3+$ BMP-2, (c) condition TGF- $\beta 1+$ IGF-1, (d) condition TGF- $\beta 3+$ IGF-1, (e) Condition TGF- $\beta 1+B M P-7$ and (f) Condition TGF$\beta 3+$ BMP-7. Scale bar: $200 \mu \mathrm{m}$ and $n=3$ donors.

further check for collagen type II and type I staining and gene expression analysis. Histomorphological outcomes with Alcian blue demonstrated that chondrogenic medium containing TGF- $\beta 3+$ BMP- 2 was the best chondrogenic medium for HFPSCs, whereas the combination TGF- $\beta 1$ and BMP-2 was the best alternative for SMSCs (Fig. 4d,e). ACs spheroids demonstrated good cartilage-like features with all combinations of growth factors (Fig. 3 and 4). None of the chondrogenic media tested was sufficient to differentiate UCSCs-MC into cartilage-forming cells (Fig. 3 and 4). Chondrogenic medium containing TGF- $\beta 3$ and BMP-2 was successful at inducing chondrogenesis with all three types of adult tissue cells and therefore this growth factor combination was used in further analyses, also with UCSCs-MC. All UCSCs-MC spheroids were characterised by low Alcian blue staining, low collagen type II staining, scant extracellular matrix and irregular cell shape. Semi-quantitative scoring for cartilage-like features 

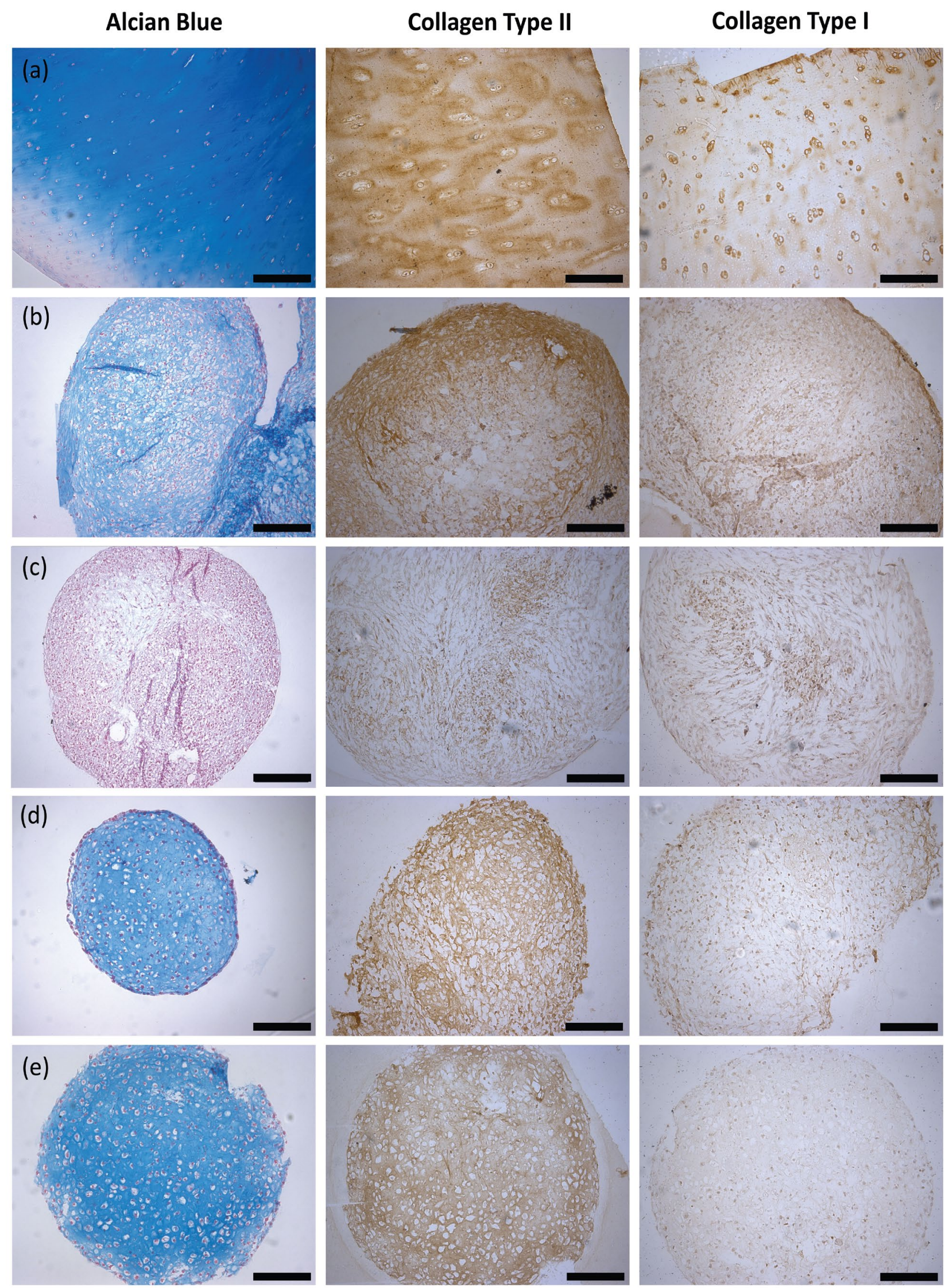

Fig. 4a-e. Bright light microscopy images of thin sections $(4 \mu \mathrm{m})$ of 3D spheroids stained with Alcian blue, collagen-II and collagen-I. (a) Cartilage, (b) ACs in the presence of TGF- $\beta 3+B M P-2$, (c) UCSCs-MC in the presence of TGF$\beta 3+$ BMP-2, (d) HFPSCs in the presence of TGF- $\beta 3+$ BMP-2 and (e) SMSCs in the presence of TGF- $\beta 1+$ BMP- 2 . Scale bar: $200 \mu \mathrm{m}$. 


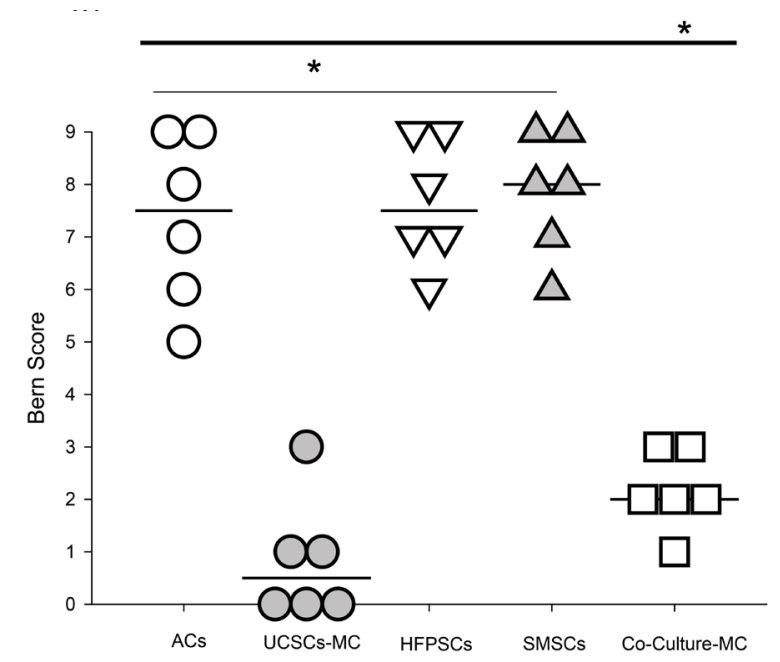

Fig. 4f. Semi-quantitative analysis representing histological scoring of Alcian blue stained 3D spheroids. (*) Shows levels of significance with $p<0.005$ and $n=3$ donors (per donor 2 samples were analysed).

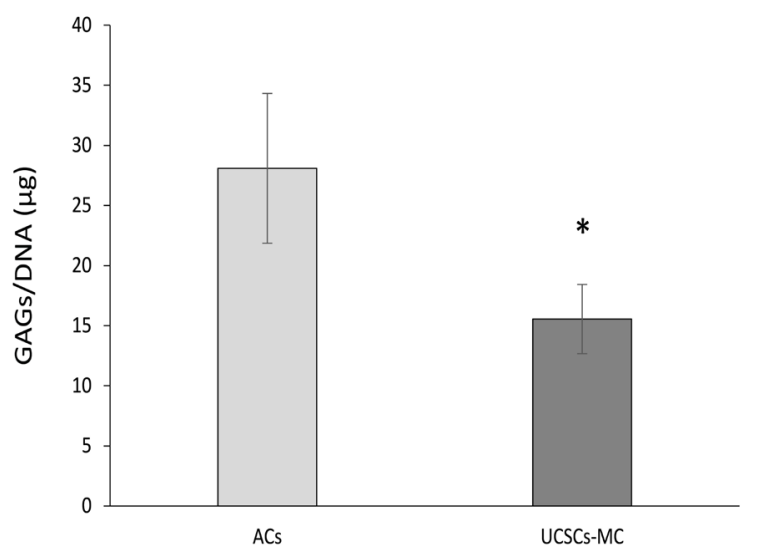

Fig. 5. Comparison of GAGs/DNA $(\mu g)$ between ACs and UCSCs-MC of three weeks old pellets in the presence of TGF- $\beta 3+$ BMP-2. Data shown are Mean \pm Standard Deviation from three different donors and (*) shows levels of significance with $p<0.05$.

after incubation with the best chondrogenic medium for each cell type showed no differences among ACs, HFPSCs and SMSCs (Table 4), but significant lower values for UCSCs-MC compared with the rest (Fig. 4f). Furthermore, immunostaining of spheroids against collagen type II and type I also demonstrated high expression of collagen type II in spheroids from ACs, HFPSCs and SMSCs, which resembles the collagen type II staining of native cartilage, and low expression in UCSCs-MC spheroids (Fig. 4). In contrast, collagen type I staining was relatively weak in spheroids from ACs, HFPSCs and SMSCs. For UCSCs$\mathrm{MC}$, due to low matrix formation in general, both collagen type II and type I staining were weak (Fig. 4).

\section{Comparative analysis of GAGs and gene expression}

To add further support to the observations gathered by histology and immunohistochemistry, chondrogenesis was assessed by measuring GAGs content in spheroids, and the expression of cartilage signature genes in best growth factors combination. In line with results from histological
Table 4. Bern Score of Alcian blue stained spheroids.

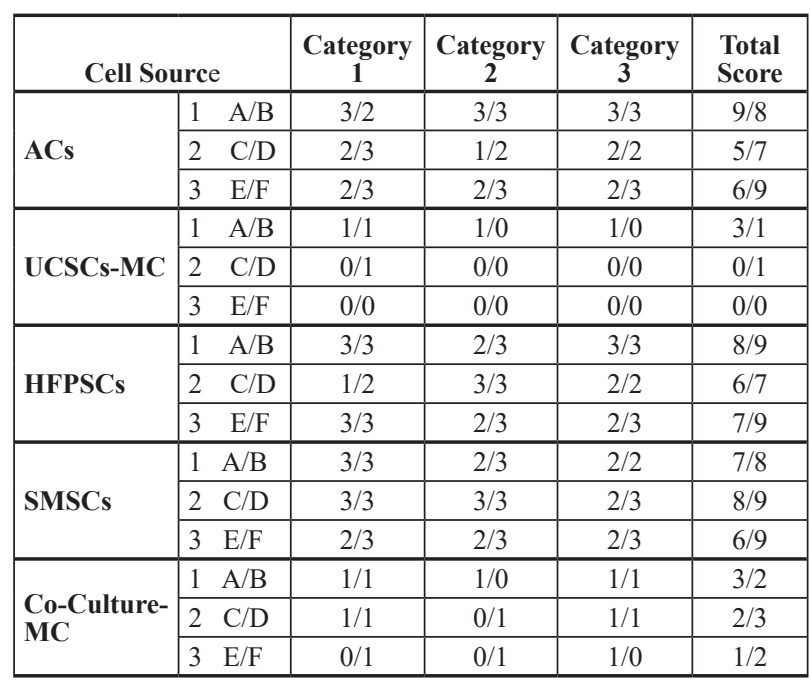

scoring, similar differences in GAGs production were observed between ACs and UCSCs-MC $(p<0.05)$ after normalising content of GAGs to the amount of DNA (Fig. 5). Spheroids from ACs produced 28.1 \pm 6.2 GAGs/DNA $(\mu \mathrm{g})$, whereas spheroids from UCSCs-MC produced $15.1 \pm 2.1 \mathrm{GAGs} / \mathrm{DNA}(\mu \mathrm{g})$. Furthermore, gene expression analysis by qPCR demonstrated that the expression of COL1A1 was similar for all cell types. However, COL2A1, aggrecan and the transcription factor SOX9 were significantly downregulated in UCSCs-MC compared to spheroids from ACs and the other two MSCs types (Fig. 6). Gene expression analyses revealed also that UCSCs-MC spheroids did not express COL9A1 and little or no COL10A1. Of note, HFPSCs had significantly higher expression levels of the proteoglycan versican and the hypertrophic chondrocyte marker COL10A than ACs spheroids, which could reveal a tendency of this MSCs source to form deep zone-type/hypertrophic cartilage. To check the differentiation status of UCSCs-MC before and after 3D culturing, we checked the expression of several SRTF genes including OCT4A, NANOG and SOX2 in monolayers and spheroids at different oxygen tensions. SRTF gene expression revealed that UCSCs-MC express these SRTF genes during monolayer cultures at both high and low oxygen (Fig. 7). Of note, expression of SRTF genes was downregulated in UCSCs-MC upon 3D culture, even when this incubation was carried out at low oxygen tensions.

\section{Ultrastructural examination of 3D constructs}

Transmission electron microscopy was used for ultrastructural evaluation of spheroids from ACs, UCSCs-MC, HFPSCs and SMSCs. This technique permits the visualisation of cellular and extracellular matrix characteristics that is not achievable with other microscopic techniques. Hence, spheroids from ACs, HFPSCs and SMSCs showed abundant inter-territorial matrix between cells, where randomly oriented collagen fibrils were easily identifiable (small arrows in images, Fig. 8). Of note, cells in spheroids from all cell sources had a round-shape morphology, had well organised cytoplasm with numerous organelles, and presented no signs of cell 

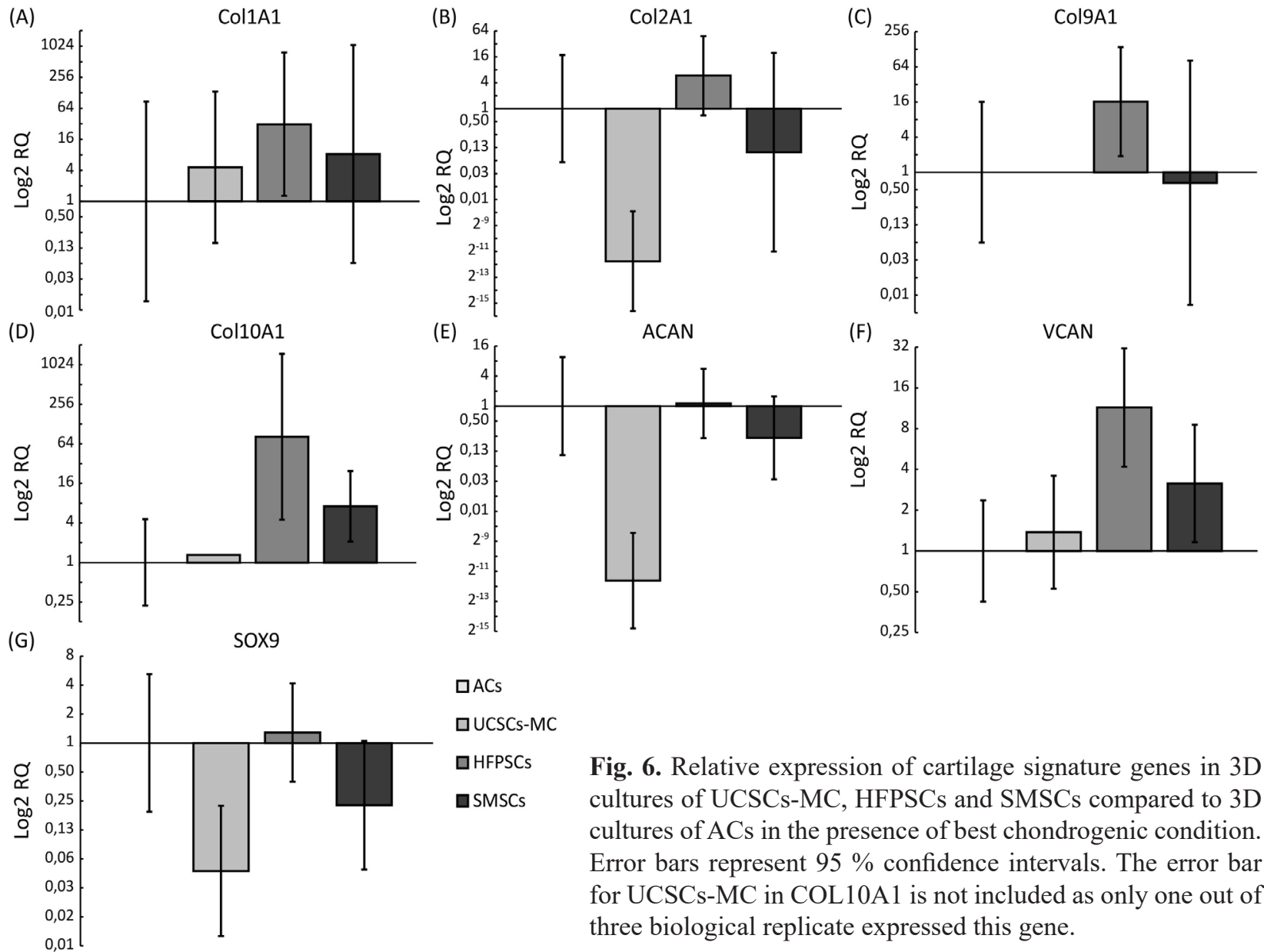

口ACS

口UCSCS-MC

口HFPSCS Fig. 6. Relative expression of cartilage signature genes in 3D $\square$ IMSCS cultures of UCSCs-MC, HFPSCs and SMSCs compared to 3D cultures of ACs in the presence of best chondrogenic condition. Error bars represent $95 \%$ confidence intervals. The error bar for UCSCs-MC in COL10A1 is not included as only one out of three biological replicate expressed this gene.

death. On the other hand, cells in UCSCs-MC spheroids were more densely packed, had more irregular and less matrix, characterised by some electron dense structures, vacuole-like structures and few collagen fibrils (Fig. 8b and 9). In addition, HFPSCs and UCSCs-MC were rich in fat droplets (Fig. 8).

UCSCs-MCs chondrogenesis in co-culture conditions Previous studies have suggested that the anabolic factor BMP-7, also known as osteogenic protein 1 (OP-1), may act synergistically with TGF- $\beta 1$ inducing chondrogenesis of MSCs from different sources in pellet culture systems (Kim and Im, 2009; Kurth et al., 2007). Based on these previous observations, and considering that our earlier attempts to induce chondrogenesis in UCSCs-MC were unsuccessful, we also studied the response of UCSCs-MC to alternative combinations of growth factors that included BMP-7 (Fig. 3). Once again, none of the new GFs combinations was able to significantly affect chondrogenesis of UCSCs-MCs, as all spheroids were characterised by high cell density, little extracellular matrix and weak Alcian blue staining (Fig. 3).

In a last attempt to induce chondrogenesis from UCSCs-MCs, spheroids were put into co-culture with either cartilage explants or freshly isolated synovial cells (Fig. 10a,b). Results from Alcian blue staining (Fig. 4f) again reveal poor chondrogenic capacity of UCSCs-MCs even in the presence of natural elements of the joint (Fig. $10 \mathbf{c}, \mathbf{d})$.

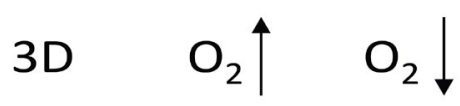

OCT $3 / 4$

SOX2

NANOG

APRT

Fig.7. Gene expression of stemness-related transcriptional factors OCT3/4, SOX2 and NANOG in 3D spheroids $\left(3 \% \mathrm{O}_{2}\right)$ and monolayer cultures at both atmospheric $(21 \%) \mathrm{O}_{2}$ levels and low $(3 \%) \mathrm{O}_{2}$ level. APRT is included for RNA quality control.

\section{Discussion}

The main goal in this study was to check the bona fide capacity of stromal cells isolated from umbilical cord to make cartilage in vitro, and to compare it with adult stromal cells harvested from other sources. By the use of different quantitative approaches and different culture conditions, we show here that, in contrast to what is observed with 

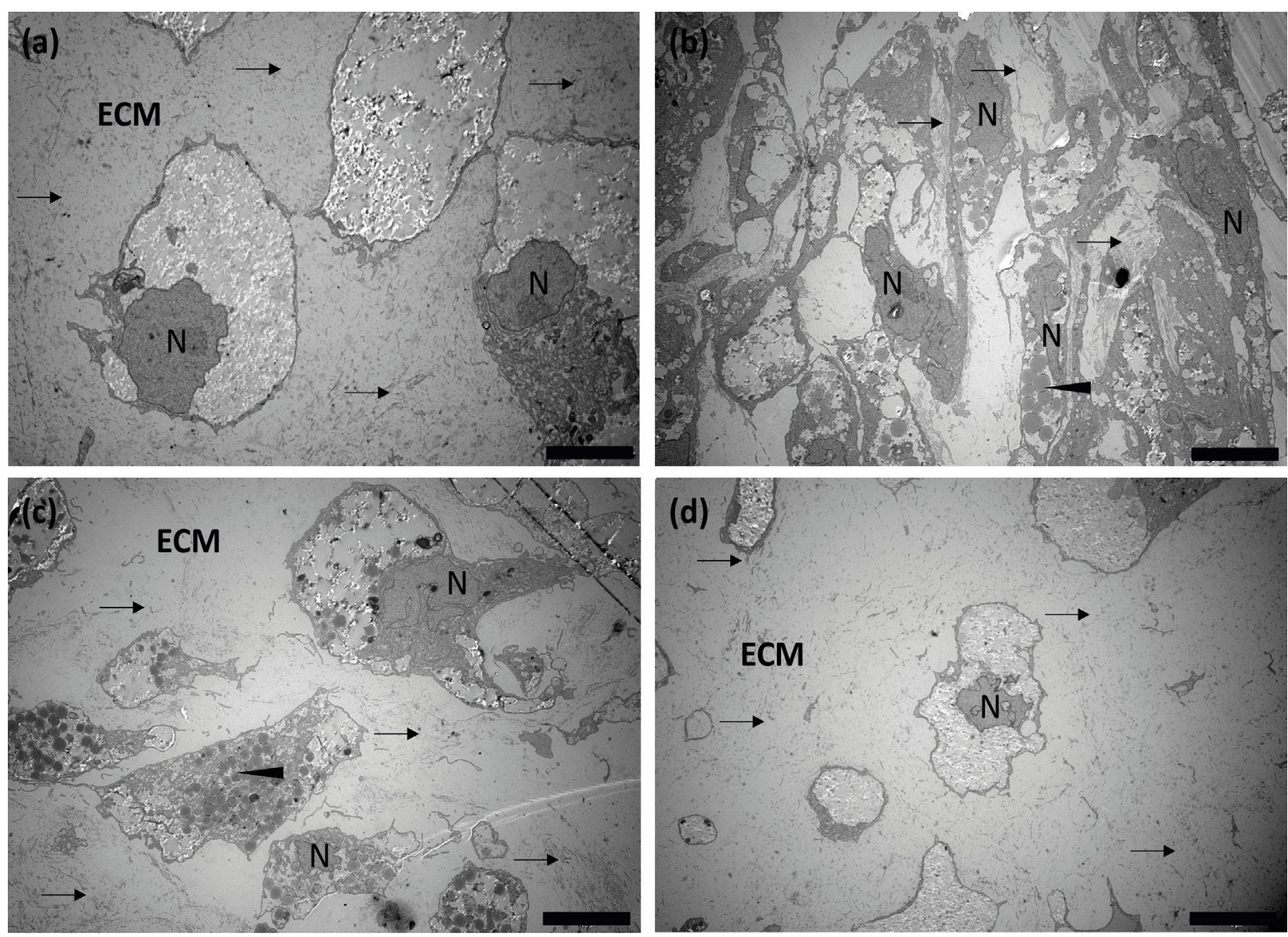

Fig. 8. Transmission Electron Microscopy (TEM) images of ultra-thin sections of 3D spheroids in the best chondrogenic conditions for each cell type. (a) ACs in the presence of TGF- $\beta 3+\mathrm{BMP}-2$, (b) UCSCs-MC in the presence of TGF- $\beta 3+$ BMP-2, (c) HFPSCs in the presence of TGF- $\beta 3+$ BMP-2 and (d) SMSCs in the presence of TGF- $\beta 1+$ BMP-2. Symbols: $N=$ Cell nuclei, $($ ECM $)=$ Extracellular matrix, $(\rightarrow)=$ Collagen fibres and $(\varangle)=$ Fat droplets. Scale bar: $10 \mu \mathrm{m}$.

stromal cells collected from synovial compartments or with chondrocytes, UCSCs-MC display low chondrogenic potential in scaffold-free $3 \mathrm{D}$ cultures, even under the influence of differentiated cells from the joint.

In our study, we have used stromal cells harvested from whole cord. It has been shown that MSCs with multipotent abilities may be isolated from different regions of the cord. However, in comparative studies it has been demonstrated that cells from all regions display very similar growth kinetics and immunoprofiles (Mennan et al., 2013; Subramanian et al., 2015). Additionally, these studies reveal that differentiation potential towards adipogenic, osteogenic and to some extent chondrogenic lineages are better achieved by cells from Wharton's jelly and whole cord. At our laboratory, we have also tested and compared chondrogenic potential of MSCs from Wharton's jelly and whole cord, both cell sources exhibiting equally low chondrogenic differentiation potential (data not shown). Due to the easier processing, we decided to use stromal cells from whole cord in this study.

Different methods including enzymatic and nonenzymatic have been reported for successful isolation of MSCs from umbilical cords (Choudhery et al., 2013; Mennan et al., 2013). Here we have used a mixed enzymatic-explant method in which tissue biopsies were briefly treated with enzyme to disrupt the membrane followed by explant culture. This method helps to avoid excessive enzymatic digestion and to reduce the time for explant culture. In line with other studies, isolated MSCs demonstrated fibroblast-like characteristics and plastic adherence in in vitro culture (Baksh et al., 2007; Vinardell et al., 2012). Unlike most published literatures, we observed UCSCs-MC grow slowly in early passages compared to HFPSCs and SMSCs and their proliferation rate increased after first sub-culture, which was also observed previously from stromal cells isolated from Wharton's jelly (Chen et al., 2012).

Phenotypic comparison by surface markers of isolated MSCs also demonstrated that UCSCs-MC, HFPSCs and SMSCs positively expressed the classical stromal cell markers CD73, CD90, and CD105, and lack expression of CD11b, CD19, CD34, CD45 and HLA-DR as previously shown in the literature (Dominici et al., 2006). Furthermore, we studied additional markers including CD44, CD106, CD146, CD166 and CD271 to investigate chondrogenic specific lineages. Arufe et al. reported that cell populations collected from human synovial membranes with high expression of CD271 and low expression of 

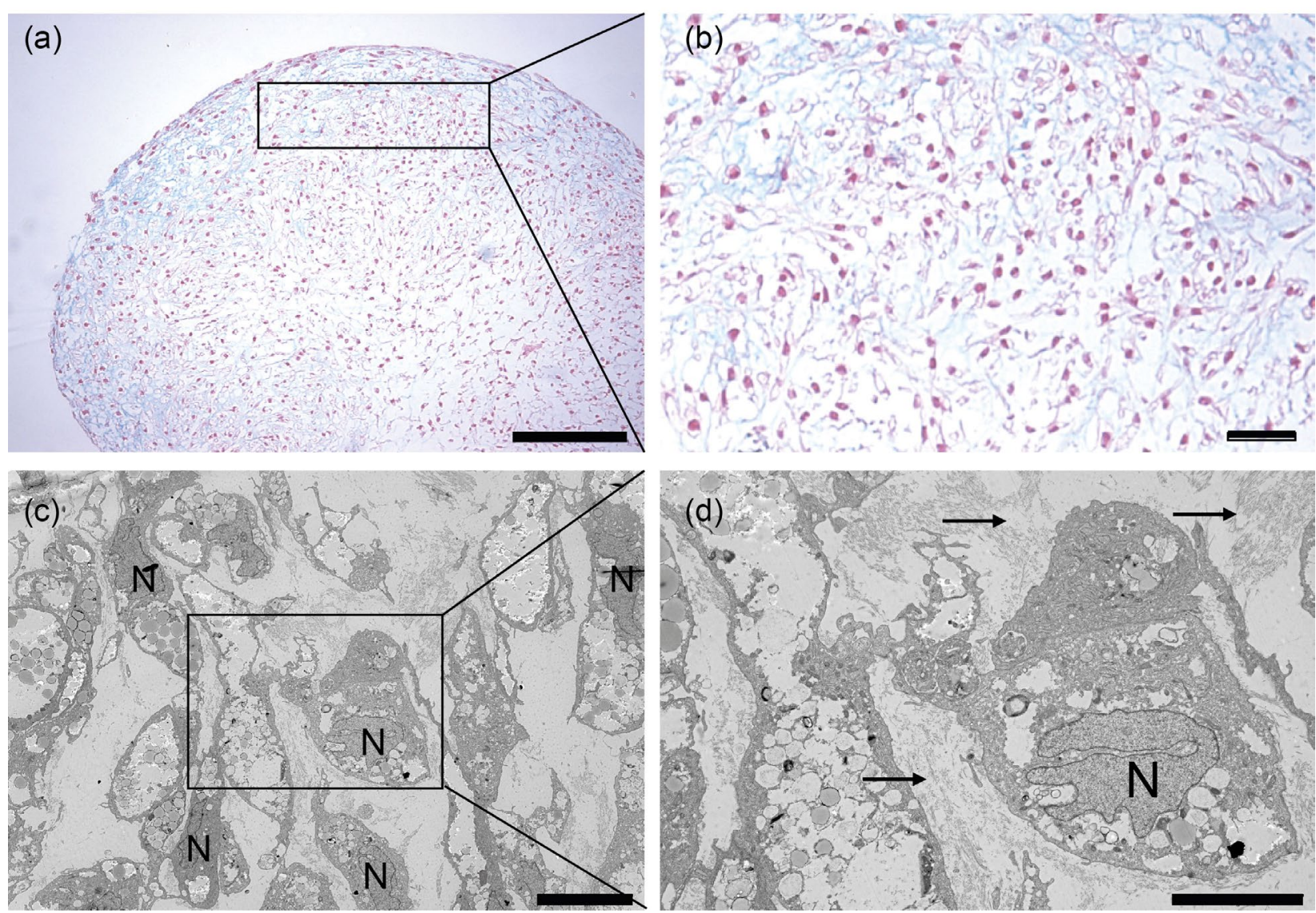

Fig. 9. Comparative Alcian blue and TEM images of UCSCs-MC spheroids at low and high magnification. (a) Alcian blue image at lower magnification (Scale bar: $200 \mu \mathrm{m}$ ), (b) Alcian blue image at higher magnification (Scale bar: $50 \mu \mathrm{m}$ ), (c) TEM image at low magnification (Scale bar: $10 \mu \mathrm{m}$ ) and (d) TEM image at high magnification (Scale bar: $5 \mu \mathrm{m})$. Symbols: $\mathrm{N}=$ Cell nuclei and $(\rightarrow)=$ Collagen fibres.

(a)
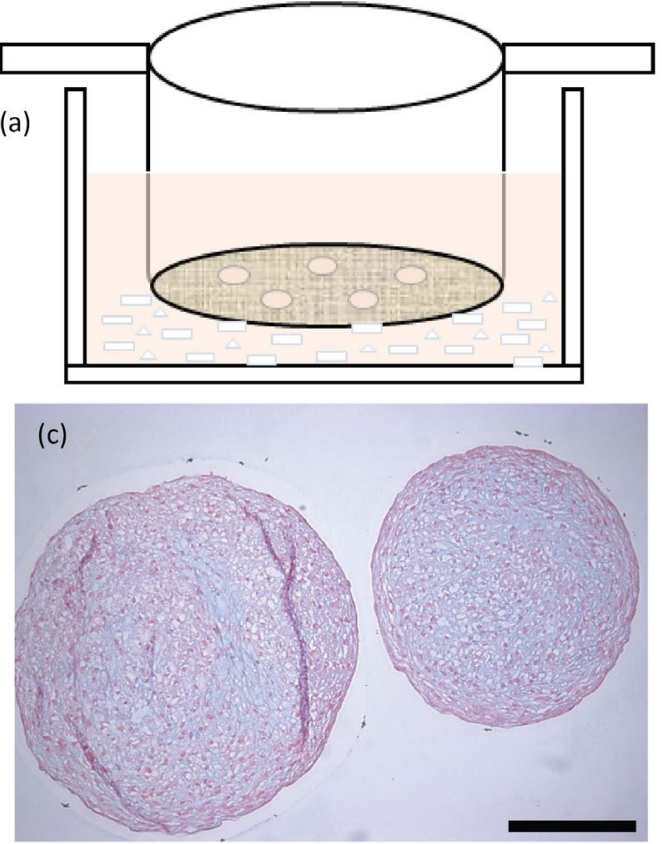
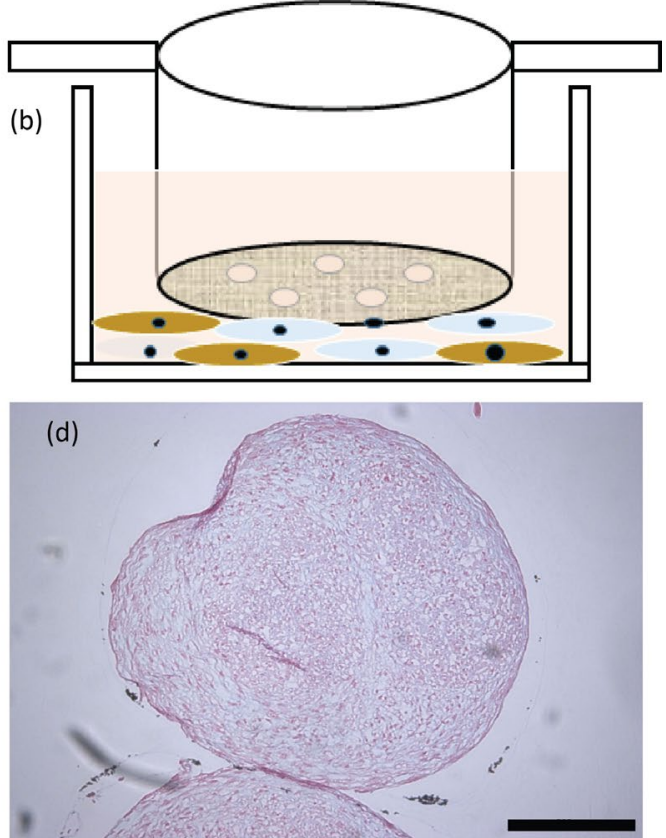

Fig. 10. Chondrogenesis of UCSCs-MC in co-culture with cartilage explants or cultured synovial cells in the presence of TGF- $\beta 3+$ BMP-2. Schematic images of experimental set up during co-culture (a) with cartilage explants; and (b) with mixed HFPSCs and SMSCs in monolayers. (c) and (d) bright light microscopy images of thin sections of UCSCs-MC spheroids stained with Alcian blue after co-culture. Scale bar: $200 \mu \mathrm{m}$ and $\mathrm{n}=3$ donors. 
CD106 possess higher chondrogenic potential (Arufe et al., 2010). Additionally, other studies also revealed that expression of CD44, CD146 and CD166 in cell populations from umbilical cord showed differentiation ability towards chondrogenic lineage (Ali et al., 2015; Baksh et al., 2007; Lu et al., 2006). Hence, we checked expression of these additional markers in all MSC cell types. Our results show uniform expression of CD44 and CD166 in all three cell sources, and absolute negative expression of CD106 and CD271. However, we have seen clear differences in the chondrogenic potential between the cells sources, altogether indicating that the set of markers included in this study were not good for predicting chondrogenic differentiation abilities. An exception could perhaps be done with CD146. We observed that over $99 \%$ of UCSCSMCs express this receptor; however, HFPSCs and SMSCs show a subpopulation of cells that are negative for CD146. The predictive value for chondrogenesis of this cell surface marker could be further investigated by sorting positive and negative cells within the HFPSCs or SMCSs populations followed by chondro-induction in 3D cultures.

For chondrogenesis, in our study we have used the pellet culture method in conical-bottom multiwell plates, which is relatively easy to perform and permits reproducible outcomes. Additionally, we have used different combinations of growth factors to test chondrogenic potential in vitro in hypoxic environment. The panel of anabolic factors chosen in this study are in line with the most widely used growth factors for chondrogenesis. In our hands, the best combination for chondro-induction of HFPSCs and SMCSs were TGF- $\beta 3$ and TGF- $\beta 1$ respectively, in combination with BMP-2 and dexamethasone. These outcomes are also in line with previous studies showing chondrogenic differentiation of HFPSCs and SMSCs (Ding et al., 2015; Vinardell et al., 2012).

In this study, UCSCs-MC showed poor differentiation potential toward the chondrogenic lineage compared with other adult stromal cells, irrespective of the presence of growth factors in the chondrogenic medium. Of note, we have deliberately used quantitative approaches to measure chondrogenesis in different ways, and we have used de-differentiated articular chondrocytes (ACs) as the "gold standard". When compared to spheroids from ACs, UCSCs-MC demonstrated a lack of matrix production, densely packed cells and poor cartilage like morphology, which was confirmed by Alcian blue staining, collagen type II immunostaining, GAG content and electron microscopy. Furthermore, we studied gene expression analysis of seven cartilage related genes in which favourable articular cartilage gene expression profile includes low levels of COL1A1, COL10A1 and VCAN, while upregulation of ACAN, SOX9, COL2A1 and COL9A1. Compared to ACs, spheroids from UCSCs-MC showed a significant downregulation of COL2A1, ACAN and SOX9, which in turn demonstrate their poor differentiation ability towards a chondrogenic lineage.

In line with our studies, Hildner et al. and Mennan et al. demonstrated poor chondrogenesis UCSCs-MC using pellet culture system, while Wang et al. showed similar results in scaffold-based cultures (Hildner et al., 2010; Mennan et al.,
2013; Wang et al., 2009b). Both Hildner et al. and Wang et al. question the hyaline cartilage transformation ability of umbilical cord stromal cells and rather emphasising on their fibrocartilage formation ability. Unlike these studies, chondrogenesis of umbilical cord stromal cells has been demonstrated in other studies using similar culturing conditions (Choudhery et al., 2013; Nirmal and Nair, 2013; Subramanian et al., 2015). Choudhery et al. demonstrated chondrogenesis of UCSCs isolated by explant method, in pellet culture condition using commercial chondrogenic medium, while Nirmal and Nair showed chondrogenesis of UCSCs isolated by enzymatic digestion, in scaffold-based culture using different combinations of TGF- $\beta 2$ and BMP2. Particular isolation or culturing procedures supporting chondrogenesis of stromal cells from UCSCs cannot be withdrawn from these studies.

Of relevance, none of these studies includes hypoxia during chondrogenesis. A recent study by Reppel et al. demonstrated better chondrogenesis of stromal cells from Wharton's Jelly in hypoxic condition (Reppel et $a l ., 2014)$. On the contrary, cell expansion in low oxygen environments has been suggested to maintain UCSCs in undifferentiated state (Drela et al., 2014). In our study, expression of OCT4A, NANOG and SOX2 is elevated in UCSCs-MC during monolayer expansion in both normoxic and hypoxic environments (albeit at higher levels in low oxygen conditions), which evidently shows that cells are kept in undifferentiated state during monolayer growth. Intriguingly, there was no expression of SRTF genes in UCSCs-MC spheroids at low oxygen levels, suggesting a transition of cells towards a differentiated phenotype, which certainly was not cartilage. Taking together, these observations indicate that hypoxia is not responsible for restraining chondrogenesis of UCSCs-MC.

A potential rationale behind the poor chondrogenesis displayed by UCSCs-MC in vitro might rely on low TGF receptor expression induced by BMP-2 stimulation, as demonstrated in adipose tissue derived stromal cells (Hennig et al., 2007). However, changing BMP-2 by BMP-7 as chondrogenic factor had no major effects (Fig. 3). On the other hand, CD105 (endoglin), a member of the TGF receptor complex which binds with high affinity to TGF- $\beta 1$ and TGF- $\beta 3$ (Robledo et al., 1996), was found to be expressed by nearly all undifferentiated cell types at both high oxygen and low oxygen environments (data not shown). Further studies must be undertaken to explore expression of other receptors of the TGF $\beta$ family in UCSCs-MC before conclusions can be reached.

Spheroids from HFPSCs and SMSCs displayed an overall favourable cartilage gene expression pattern, much in line with spheroids from ACs. Of relevance, in our gene expression analyses we observe upregulation of genes such as COL10A1 and VCAN in differentiated HFPSCs. Higher expression of COL10A1 and VCAN was reported in earlier studies associated with cartilage hypertrophy and bone development, respectively (Nakamura et al., 2005; Pelttari et al., 2006). Such observations should be taken into consideration at the time of choosing HFPSCs as a cell source for cartilage tissue engineering.

In earlier studies, chondrogenesis of MSCs have been enhanced by co-culturing the stromal cells with 
chondrocytes (Fischer et al., 2010). Thus, in a new attempt to induce chondrogenesis from UCSCs-MC, we developed a co-culture system to mimic in vitro intra-articular microenvironments. Once again, UCSCs-MCs spheroids did not develop histo-morphological characteristics of articular cartilage as revealed by metachromasia. Poor chondrogenic potential of UCSCs-MC in our co-culture study could be due to the use of UCSCs-MC and ACs separately rather than using in the same spheroids as previous studies shown (Bian et al., 2011).

\section{Conclusions}

Here we disclose poor chondrogenic potential of UCSCs$\mathrm{MC}$, at least under the conditions tested in the present study. However, it is becoming increasingly accepted that undifferentiated stromal cells might act as adjuvant elements during tissue healing, not by building new tissue themselves but rather by modulating the local environment, making it more favourable for anabolic processes (Liu et al., 2012). Thus, despite their low chondrogenic differentiation potential, stromal cells from the umbilical cord might still be considered for transplantation strategies as facilitators of tissue repair. The precise mechanism of action and the potential therapeutic effects of these cells is yet to be elucidated.

\section{Acknowledgements}

This work is supported by University of Tromsø and Arthritis Research UK (CM, via grant No. 19429). The authors sincerely thank Dr. Gunnar Knutsen and Geir Tore Abrahamsen, University Hospital of North Norway (UNN), for providing cartilage and Hoffa's fat pad biopsies, Åse Vårtun for providing umbilical cord, Kirsti Rønne for preparing sections for histology, Jerusalem for doing cell culture and Augusta Aspar for taking TEM images.

\section{References}

Ali H, Al-Yatama MK, Abu-Farha M, Behbehani K, Al Madhoun A (2015) Multi-lineage differentiation of human umbilical cord Wharton's Jelly Mesenchymal Stromal Cells mediates changes in the expression profile of stemness markers. PLoS One 10: e0122465.

Arufe MC, De la Fuente A, Fuentes I, de Toro FJ, Blanco FJ (2010) Chondrogenic potential of subpopulations of cells expressing mesenchymal stem cell markers derived from human synovial membranes. J Cell Biochem 111: 834-845.

Bailey MM, Wang L, Bode CJ, Mitchell KE, Detamore MS (2007) A comparison of human umbilical cord matrix stem cells and temporomandibular joint condylar chondrocytes for tissue engineering temporomandibular joint condylar cartilage. Tissue Eng 13: 2003-2010.

Baksh D, Yao R, Tuan RS (2007) Comparison of proliferative and multilineage differentiation potential of human mesenchymal stem cells derived from umbilical cord and bone marrow. Stem Cells 25: 1384-1392.

Beris AE, Lykissas MG, Papageorgiou CD, Georgoulis AD (2005) Advances in articular cartilage repair. Injury 36 Suppl 4: S14-23.

Bian L, Zhai DY, Mauck RL, Burdick JA (2011) Coculture of human mesenchymal stem cells and articular chondrocytes reduces hypertrophy and enhances functional properties of engineered cartilage. Tissue Eng Part A 17: 1137-1145.

Brittberg M (2008) Autologous chondrocyte implantation - technique and long-term follow-up. Injury 39 Suppl 1: S40-49.

Chen HC, Lee YS, Sieber M, Lu HT, Wei PC, Wang CN, Peng HH, Chao AS, Cheng PJ, Chang SD, Chen SJ, Wang TH (2012) MicroRNA and messenger RNA analyses of mesenchymal stem cells derived from teeth and the Wharton jelly of umbilical cord. Stem Cells Dev 21: 911922.

Choudhery MS, Badowski M, Muise A, Harris DT (2013) Comparison of human mesenchymal stem cells derived from adipose and cord tissue. Cytotherapy 15: 330-343.

Ding DC, Wu KC, Chou HL, Hung WT, Liu HW, Chu TY (2015) Human infrapatellar fat pad-derived stromal cells have more potent differentiation capacity than other mesenchymal cells and can be enhanced by hyaluronan. Cell Transplant 24: 1221-1232.

Dominici M, Le Blanc K, Mueller I, Slaper-Cortenbach I, Marini F, Krause D, Deans R, Keating A, Prockop D, Horwitz E (2006) Minimal criteria for defining multipotent mesenchymal stromal cells. The International Society for Cellular Therapy position statement. Cytotherapy 8: 315 317.

Drela K, Sarnowska A, Siedlecka P, SzablowskaGadomska I, Wielgos M, Jurga M, Lukomska B, Domanska-Janik K (2014) Low oxygen atmosphere facilitates proliferation and maintains undifferentiated state of umbilical cord mesenchymal stem cells in an hypoxia inducible factor-dependent manner. Cytotherapy 16: 881892.

El Omar R, Beroud J, Stoltz JF, Menu P, Velot E, Decot V (2014) Umbilical cord mesenchymal stem cells: the new gold standard for mesenchymal stem cell-based therapies? Tissue Eng Part B Rev 20: 523-544.

Filardo G, Vannini F, Marcacci M, Andriolo L, Ferruzzi A, Giannini S, Kon E (2013) Matrix-assisted autologous chondrocyte transplantation for cartilage regeneration in osteoarthritic knees: results and failures at midterm followup. Am J Sports Med 41: 95-100.

Fischer J, Dickhut A, Rickert M, Richter W (2010) Human articular chondrocytes secrete parathyroid hormonerelated protein and inhibit hypertrophy of mesenchymal stem cells in coculture during chondrogenesis. Arthritis Rheum 62: 2696-2706.

Fong CY, Subramanian A, Gauthaman K, Venugopal J, Biswas A, Ramakrishna S, Bongso A (2012) Human umbilical cord Wharton's jelly stem cells undergo enhanced chondrogenic differentiation when grown on nanofibrous scaffolds and in a sequential two-stage culture medium environment. Stem Cell Rev 8: 195-209. 
Grogan SP, Barbero A, Winkelmann V, Rieser F, Fitzsimmons JS, O’Driscoll S, Martin I, Mainil-Varlet P (2006) Visual histological grading system for the evaluation of in vitro-generated neocartilage. Tissue Eng 12: 2141-2149.

Hennig T, Lorenz H, Thiel A, Goetzke K, Dickhut A, Geiger F, Richter W (2007) Reduced chondrogenic potential of adipose tissue derived stromal cells correlates with an altered TGFbeta receptor and BMP profile and is overcome by BMP-6. J Cell Physiol 211: 682-691.

Hildner F, Wolbank S, Redl H, van Griensven M, Peterbauer A (2010) How chondrogenic are human umbilical cord matrix cells? A comparison to adiposederived stem cells. J Tissue Eng Regen Med 4: 242-245.

Horas U, Pelinkovic D, Herr G, Aigner T, Schnettler R (2003) Autologous chondrocyte implantation and osteochondral cylinder transplantation in cartilage repair of the knee joint. A prospective, comparative trial. J Bone Joint Surg Am 85-A: 185-192.

Hunziker EB (2002) Articular cartilage repair: basic science and clinical progress. A review of the current status and prospects. Osteoarthritis Cartilage 10: 432-463.

Ivascu A, Kubbies M (2006) Rapid generation of single-tumor spheroids for high-throughput cell function and toxicity analysis. J Biomol Screen 11: 922-932.

Kim HJ, Im GI (2009) Combination of transforming growth factor-beta2 and bone morphogenetic protein 7 enhances chondrogenesis from adipose tissue-derived mesenchymal stem cells. Tissue Eng Part A 15: 1543-1551.

Knutsen G, Drogset JO, Engebretsen L, Grontvedt T, Isaksen V, Ludvigsen TC, Roberts S, Solheim E, Strand T, Johansen O (2007) A randomized trial comparing autologous chondrocyte implantation with microfracture. Findings at five years. J Bone Joint Surg Am 89: 2105 2112.

Kurth T, Hedbom E, Shintani N, Sugimoto M, Chen FH, Haspl M, Martinovic S, Hunziker EB (2007) Chondrogenic potential of human synovial mesenchymal stem cells in alginate. Osteoarthritis Cartilage 15: 1178-1189.

Liu S, Yuan M, Hou K, Zhang L, Zheng X, Zhao B, Sui X, Xu W, Lu S, Guo Q (2012) Immune characterization of mesenchymal stem cells in human umbilical cord Wharton's jelly and derived cartilage cells. Cell Immunol 278: $35-44$.

Lu LL, Liu YJ, Yang SG, Zhao QJ, Wang X, Gong W, Han ZB, Xu ZS, Lu YX, Liu D, Chen ZZ, Han ZC (2006) Isolation and characterization of human umbilical cord mesenchymal stem cells with hematopoiesis-supportive function and other potentials. Haematologica 91: 10171026.

Maleki M, Ghanbarvand F, Reza Behvarz M, Ejtemaei M, Ghadirkhomi E (2014) Comparison of mesenchymal stem cell markers in multiple human adult stem cells. Int J Stem Cells 7: 118-126.

McDowell EM, Trump BF (1976) Histologic fixatives suitable for diagnostic light and electron microscopy. Arch Pathol Lab Med 100: 405-414.

Meknas K, Johansen O, Steigen SE, Olsen R, Jorgensen L, Kartus J (2012) Could tendinosis be involved in osteoarthritis? Scand J Med Sci Sports 22: 627-634.
Mennan C, Wright K, Bhattacharjee A, Balain B, Richardson J, Roberts S (2013) Isolation and characterisation of mesenchymal stem cells from different regions of the human umbilical cord. BioMed Research Int 2013: 916136.

Mueller SM, Glowacki J (2001) Age-related decline in the osteogenic potential of human bone marrow cells cultured in three-dimensional collagen sponges. J Cell Biochem 82: 583-590.

Nakamura M, Sone S, Takahashi I, Mizoguchi I, Echigo S, Sasano Y (2005) Expression of versican and ADAMTS1, 4 , and 5 during bone development in the rat mandible and hind limb. J Histochem Cytochem 53: 1553-1562.

Nirmal RS, Nair PD (2013) Significance of soluble growth factors in the chondrogenic response of human umbilical cord matrix stem cells in a porous three dimensional scaffold. Eur Cell Mater 26: 234-251.

Park YB, Song M, Lee CH, Kim JA, Ha CW (2015) Cartilage repair by human umbilical cord blood-derived mesenchymal stem cells with different hydrogels in a rat model. J Orthop Res 33: 1580-1586.

Pelttari K, Winter A, Steck E, Goetzke K, Hennig T, Ochs BG, Aigner T, Richter W (2006) Premature induction of hypertrophy during in vitro chondrogenesis of human mesenchymal stem cells correlates with calcification and vascular invasion after ectopic transplantation in SCID mice. Arthritis Rheum 54: 3254-3266.

Pretzel D, Linss S, Rochler S, Endres M, Kaps C, Alsalameh S, Kinne RW (2011) Relative percentage and zonal distribution of mesenchymal progenitor cells in human osteoarthritic and normal cartilage. Arthritis Res Ther 13: R64.

Reppel L, Margossian T, Yaghi L, Moreau P, Mercier N, Leger L, Hupont S, Stoltz JF, Bensoussan D, Huselstein C (2014) Hypoxic culture conditions for Mesenchymal Stromal/Stem Cells from Wharton's jelly: a critical parameter to consider in a therapeutic context. Curr Stem Cell Res Ther 9: 306-318.

Robledo MM, Hidalgo A, Lastres P, Arroyo AG, Bernabeu C, Sanchez-Madrid F, Teixido J (1996) Characterization of TGF-beta 1-binding proteins in human bone marrow stromal cells. Br J Haematol 93: 507-514.

Roobrouck VD, Ulloa-Montoya F, Verfaillie CM (2008) Self-renewal and differentiation capacity of young and aged stem cells. Exp Cell Res 314: 1937-1944.

Smeriglio P, Lai JH, Dhulipala L, Behn AW, Goodman SB, Smith RL, Maloney WJ, Yang F, Bhutani N (2015) Comparative potential of juvenile and adult human articular chondrocytes for cartilage tissue formation in three-dimensional biomimetic hydrogels. Tissue Eng Part A 21: 147-155.

Subramanian A, Fong CY, Biswas A, Bongso A (2015) Comparative characterization of cells from the various compartments of the human umbilical cord shows that the Wharton's jelly compartment provides the best source of clinically utilizable mesenchymal stem cells. PLoS One 10: e0127992.

Subramanian A, Shu-Uin G, Kae-Siang N, Gauthaman K, Biswas A, Choolani M, Bongso A, Chui-Yee F (2012) Human umbilical cord Wharton's jelly mesenchymal stem 
cells do not transform to tumor-associated fibroblasts in the presence of breast and ovarian cancer cells unlike bone marrow mesenchymal stem cells. J Cell Biochem 113: 1886-1895.

Tang X, Fan L, Pei M, Zeng L, Ge Z (2015) Evolving concepts of chondrogenic differentiation: history, state-ofthe-art and future perspectives. Eur Cell Mater 30: 12-27.

Toh WS, Cao T (2014) Derivation of chondrogenic cells from human embryonic stem cells for cartilage tissue engineering. Methods Mol Biol 1307: 263-279.

Troyer DL, Weiss ML (2008) Wharton's jelly-derived cells are a primitive stromal cell population. Stem Cells 26: 591-599.

Vinardell T, Sheehy EJ, Buckley CT, Kelly DJ (2012) A comparison of the functionality and in vivo phenotypic stability of cartilaginous tissues engineered from different stem cell sources. Tissue Eng Part A 18: 1161-1170.

Wang L, Seshareddy K, Weiss ML, Detamore MS (2009a) Effect of initial seeding density on human umbilical cord mesenchymal stromal cells for fibrocartilage tissue engineering. Tissue Eng Part A 15: 1009-1017.

Wang L, Tran I, Seshareddy K, Weiss ML, Detamore MS (2009) A comparison of human bone marrow-derived mesenchymal stem cells and human umbilical cord-derived mesenchymal stromal cells for cartilage tissue engineering. Tissue Eng Part A 15: 2259-2266.

Wright KT, Mennan C, Fox H, Richardson JB, Banerjee R, Roberts S (2013) Characterization of the cells in repair tissue following autologous chondrocyte implantation in mankind: a novel report of two cases. Regen Med 8: 699709.

Zhang X, Hirai M, Cantero S, Ciubotariu R, Dobrila L, Hirsh A, Igura K, Satoh H, Yokomi I, Nishimura T,
Yamaguchi S, Yoshimura K, Rubinstein P, Takahashi TA (2011) Isolation and characterization of mesenchymal stem cells from human umbilical cord blood: reevaluation of critical factors for successful isolation and high ability to proliferate and differentiate to chondrocytes as compared to mesenchymal stem cells from bone marrow and adipose tissue. J Cell Biochem 112: 1206-1218.

\section{Discussion with Reviewers}

Reviewer II: What do you think are the major differences between your work and the work in other groups that have already shown robust chondrogenic potential of umbilical cord-derived stromal cells?

Authors: We have made several allusions to this point throughout the manuscript. In our view, no previous publications are showing "robust" chondrogenic potential of UCSCs. Most of these reports focus primarily on showing multi-lineage differentiation potential of cells, do not focus on chondrogenesis, and the evidences provided are only qualitative, and at its best questionable. The few other reports that provide more quantitative approaches do not compare

expression of cartilage signature molecules with native cartilage or other cell sources, so it is not possible to ascertain the true degree of differentiation. For the rest of the reports, the conclusions are that at best UCSCs they are able to differentiate into fibrocartilage but not into hyaline cartilage.

Editor's Note: Scientific Editor in charge of the paper: Brian Johnstone 